Article

\title{
Effect of Compositions of MRT System Route Maps on Cognitive Mapping
}

\author{
Meng-Cong Zheng * (D) and Yao-Wei Liu \\ Department of Industrial Design, National Taipei University of Technology, 1, Sec. 3, Chung-hsiao E. Rd., \\ Taipei 10608, Taiwan; t107588019@ntut.org.tw \\ * Correspondence: zmcdesign@ntut.edu.tw; Tel.: +886-2-2771-2171 (ext. 2827)
}

Citation: Zheng, M.-C.; Liu, Y.-W. Effect of Compositions of MRT System Route Maps on Cognitive Mapping. ISPRS Int. J. Geo-Inf. 2021, 10, 569. https://doi.org/10.3390/ ijgi10080569

Academic Editor: Wolfgang Kainz

Received: 5 July 2021

Accepted: 20 August 2021

Published: 23 August 2021

Publisher's Note: MDPI stays neutral with regard to jurisdictional claims in published maps and institutional affiliations.

Copyright: (C) 2021 by the authors Licensee MDPI, Basel, Switzerland. This article is an open access article distributed under the terms and conditions of the Creative Commons Attribution (CC BY) license (https:// creativecommons.org/licenses/by/ $4.0 /)$.

\begin{abstract}
Route maps, common in public transportation systems, refer to thematic maps drawn according to topological concepts. To simplify complex route information, a transport network is represented using primary graphic elements. First used in 1931 with topological concepts, the octilinear design has influenced the compositions of traffic route maps to this day. The current study involved cognitive mapping research on a representative route map in Taiwan: the Metro Taipei Route Map. Through two task experiments, this study analyzed users' cognitive behavior when using the route map and alternative route map representations. The results indicated that the route map composed of all curves resulted in higher user performance than maps using a hybrid system and the conventional octilinear system. The route map based on the hybrid system, which included a route in the shape of a perfect circle, was highly evaluated and subjectively preferred by the users. Thus, the addition of appropriate curves in route maps is beneficial for improving usability, cognitive memory, and subjective evaluation. Finally, adding travel time information to a route map effectively enhances users' decision-making during route planning.
\end{abstract}

Keywords: transit map; topological map; cognitive mapping; Taipei metro

\section{Introduction}

Urban expansion and development have enhanced people's mobility. Thus, countries have implemented transit-oriented development and typically base their urban development on efficiency-improving public transport systems. However, Hickman and Wilson indicated that the complexity of public transport systems and the random information a user might access during a journey result in public transport presenting greater uncertainty than general road transport [1]. Morrison emphasized transit map representation with simple geometric lines based on topological concepts [2]; this approach enables users to monitor their progress and switch routes more easily while also rapidly understanding that the route map is not drawn to scale. Nevertheless, a user might overlook distorted route map information caused by the map not being drawn to scale. A survey by Guo [3] revealed that passengers overlooking distorted route map information could spend up to twice more time on transportation than they expected." Past studies showed distances between stations on a metro route map affected the users' decision-making regarding their public transport route; difference between a route map and the actual distance traveled might limit people's ability to avoid crowded routes. Thus, the layout design of a route map impacts decision-making, but the way the features are portrayed also affects people's route selection. Accordingly, a transit map could potentially become a planning tool to solve operational problems and improve system.

Any type of map is composed of numerous basic visual elements; a designer employs diverse symbols to represent the characteristics of a certain space. The visualization process, or thinking by incorporating visual images into thought, occurs to the fullest when seeing, imagining, and graphic ideation come into active interplay [4,5]. The point, line, and area can be regarded as the most basic graphic elements in a map [6]. Schematic transport 
maps usually have all routes drawn as straight lines. Lines vary in direction via fixed, stylized angles, commonly 45 and 90 degrees or 30,60, and 90 degrees, or are simplified with arbitrary angles. Overlapping routes are separated by a minimum legibility distance, which can be zero or a constant chosen for the particular map. Adjacent schematized lines can have smooth, artistic, circular arcs around bends, preserving their graphic proximity distance for the greatest length possible. A small number of breaks or changes in line direction can provide better visualization and add a sense of the original geometry [7]. In at least one study using thematic maps, the balance of the map's elements is shown to have an initial effect on the way the map reader goes about looking at those elements [8].

In terms of transport, designing high-quality route maps involves particular concerns. Route map design first gained attention in 1931 when Henry Beck used topological concepts to draw a map of the London Underground using $0^{\circ}, 45^{\circ}$, and $90^{\circ}$ angles. That map exerts an effect to this day. Wolff [9] referred to the design principles of Beck's map as "octilinearity" and indicated that the modality could effectively make route maps neat and organized (Figure 1). However, through the method of cognitive mapping, Vertesi [10] found that octilinear route maps significantly affected Londoners' spatial cognition and the approach they employed to determine their routes, i.e., route maps formed the basis of individuals' spatial cognition in their brains.

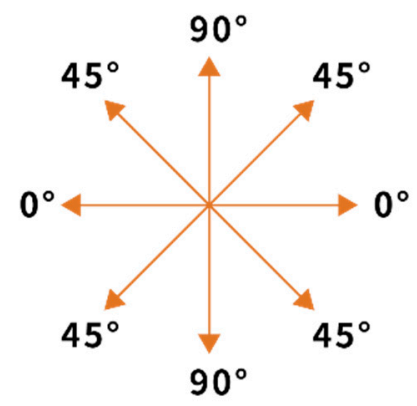

Figure 1. Schematic of octilinear route directions (Wolff, 2007).

Route maps are a tool for route planning. Robert et al. [11] argued that these maps are aimed at reducing cognitive load during trip planning. They should facilitate straightforward and rapid reconstruction of a route if planning fails. He also indicated numerous valuable design suggestions in route maps based on the conventional octilinear design, such as font and line width, maintaining a neat layout, and extending line segments. Even so, there are still some conditions to be aware of. For example, map scale is relatively large in the inner city, where many routes converge and connect; stops in the central business district might be only four or five blocks apart, and a larger scale is needed to accommodate all route lines and station names and to facilitate path finding [12,13]. Robert et al. [14] further proposed three types of route map compositions to perform a usability comparison between conventional official route maps and all-curve designs (i.e., replacing all straight lines and angles with smooth curves). The results indicated that none of the design rules could be regarded as the gold standard; when route maps based on octilinear design become ineffective under certain circumstances, design approaches that depart from conventional concepts are likely to result in usability enhancements. Nagao et al. [15] found that users could accomplish their route search and planning even in a complex transport network as long as they grasped key information such as routes, stops, and transfer stations. Their study revealed that concise graphics comprising circular lines as well as vertical and horizontal key routes helped users build their spatial cognition and that route maps should be designed in accordance with local conditions.

A schematic map is a common communication map [16] and is a type of thematic map containing considerable geographic information. A simple, comprehensive definition of 'schematic map' is difficult to determine. According to Oke and Siddiqui's study [14], a schematic map is a linear cartogram of a given network. Schematic diagrams use symbolic 
representations of pathways to reduce complexity and ease orientation in a network. How are schematic maps produced? Drafting software is often applied to support the map drawings by computer. In general, the original road network is scanned or digitized to be used as background to the drawing and design of the new schematized lines. This method requires the same degree of visual scrutiny as the manual one, because it is still a procedure of trial-and-error attempts, but results can be obtained more quickly, attempts can be stored, and output to paper can be easily arranged [17]. The cartographic literature offers some guidance for representing thematic data on routes but is apparently barren of guiding cartographic principles for the depiction of point data on routes [18].

However, the key method for conveying spatial knowledge in route maps differs from that of general map designs because route maps topologize and simplify actual geographical conditions. Route maps are commonly employed in the systems of various public transport tools; thus, understanding how route map composition affects cognitive mapping is essential. The Metro Taipei Route Map was selected as the object of this study. Composed of five routes, Taipei's metro system is currently the public transport system in Taiwan with the highest usage frequency and with an average daily ridership over 2.1 million. In this study, we first observed the route map of Taipei's metro system and investigated proposals for new designs, to identify key factors affecting users' cognition. Subsequently, we observed users' cognitive memory and behavior regarding route maps and used diverse design approaches to examine the relationships between route map composition and cognitive mapping. Finally, references and suggestions for future route map design were provided based on the research findings.

\section{Materials and Methods}

The route map of Taipei Metro, which has the largest number of converged routes and the highest ridership in Taiwan, was selected as the research object. To determine the usage status of the targeted route map, nonparticipant observation and behavior mapping were used to observe the public's usage frequency and behavior. We made nonparticipant observation at specific Taipei Metro stations, recorded 100 users who using the route map, and interviewed them about their usage habits and suggestions. We noted that the hot zones that the users' paid most attention to were largely concentrated on the dense transfer stations around Taipei Main Station on the route map. This map is used every $1.3 \mathrm{~min}$ on average on weekends and once every $2.1 \mathrm{~min}$ on weekdays based on our observation. When passengers stop to check the route map, they often also use their cell phones, discuss the matter with their companions, and observe the actual environment. In the survey, the users responded that the route map did not provide information on the travel time between stations, which hampered their ability to perform optimal journey planning within limited time.

\subsection{Experiment 1: Cognitive Mapping and Route Planning Using the Metro Taipei Route Map}

We used route maps (length $=130 \mathrm{~cm}$; width $=95.3 \mathrm{~cm}$ ) provided by the Taipei Rapid Transit Corporation, which were pasted on the walls at metro stations at an average height of $88 \mathrm{~cm}$ above the ground; the visibility range was between $30 \mathrm{~cm}$ and $125 \mathrm{~cm}$ from the wall (Figure 2). In total, 32 users (16 men and 16 women) aged 16-64 years with experience using Taipei's metro system were invited for Experiment 1. They all have university degrees. The experimental steps were as follows: (1) providing demographic information and completing an experience questionnaire; (2) performing cognitive mapping using the current route map as well as completing three tasks involving route search and three tasks involving route planning; (3) completing the Usability Metric for User Experience (UMUX) scale. 

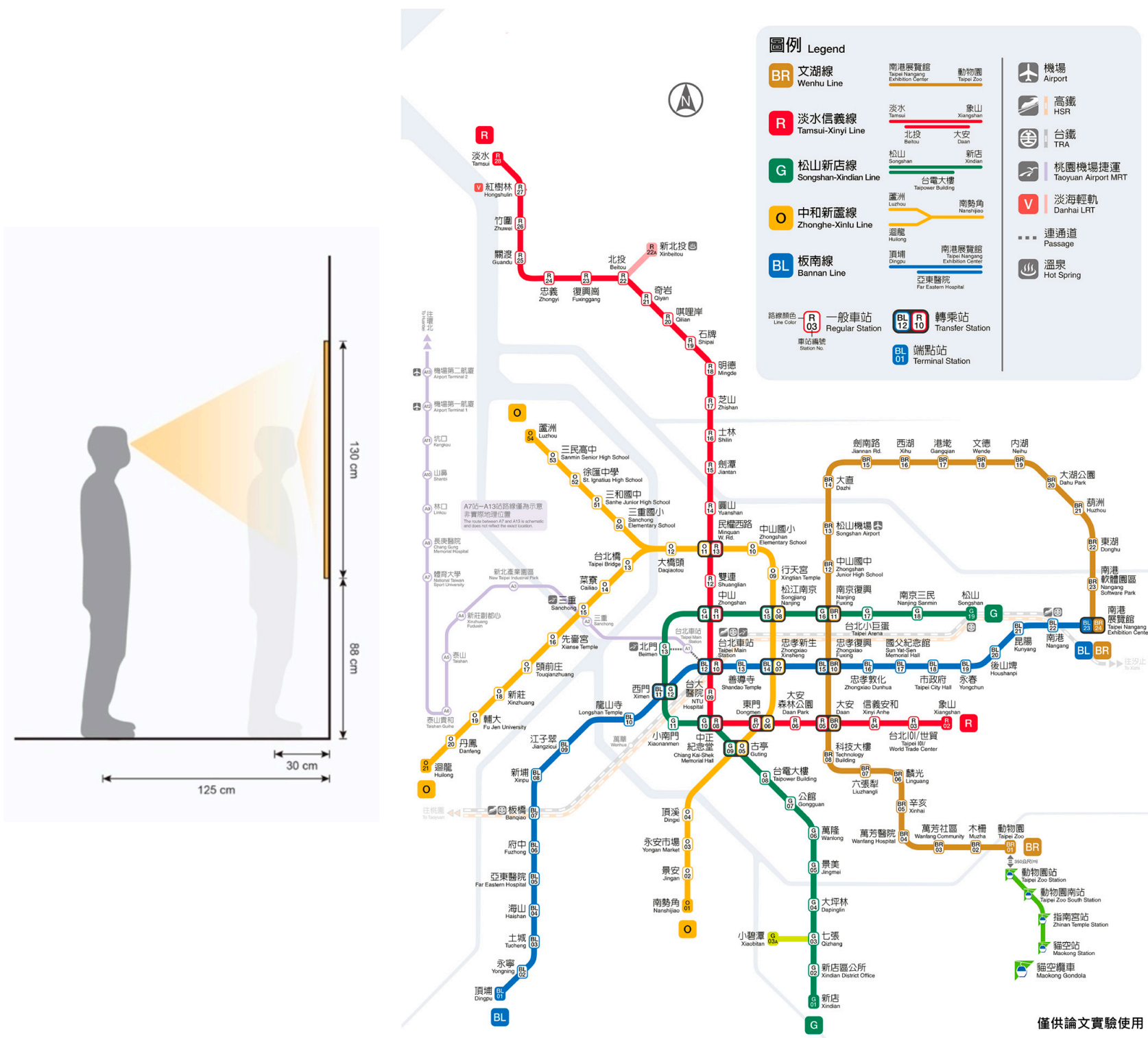

Figure 2. Present route map.

\subsection{Experiment 2: Comparison and Evaluation of New Designs for the Metro System Route Map}

After analyzing users' cognitive mapping regarding the current route map through the findings of Experiment 1, we proposed three new versions of the metro system route map. Considering that several routes in the Greater Taipei Area were under construction and to include them in the future drawing, the composition of the route maps for Experiment 2 was changed to a landscape perspective (i.e., horizontal; length $=95.3 \mathrm{~cm}$; width $=65 \mathrm{~cm}$ ) and comprised Map A, Map B, and Map C. Before each participant engaged in the experiment, a route map was stuck to the wall according to their ideal eye-level height. Prior horizontal route map studies have indicated that the optimal height above the ground was $123.2 \mathrm{~cm}$ (Figure 3). Participants in Experiment 2 preferred the center of the drawing at an eye-level height of $155.7 \mathrm{~cm}$ above the ground. Thirty users aged between 16 and 64 years with experience using Taipei's metro system were invited for this experimental phase. They all have university degrees and did not join Experiment 1 before. The participants were divided into three groups, with each group comprising 10 persons based on Zheng's evidence-based study [19], including five men and five women. Each participant used only one proposed route map for their experimental task. The experiment involved four steps: (1) A demographic information questionnaire, (2) Four route planning and cognitive 
mapping tasks, including long and short-distance routes to understanding users' diversity planning, (3) A route map evaluation scale, and (4) Route map preference ranking.

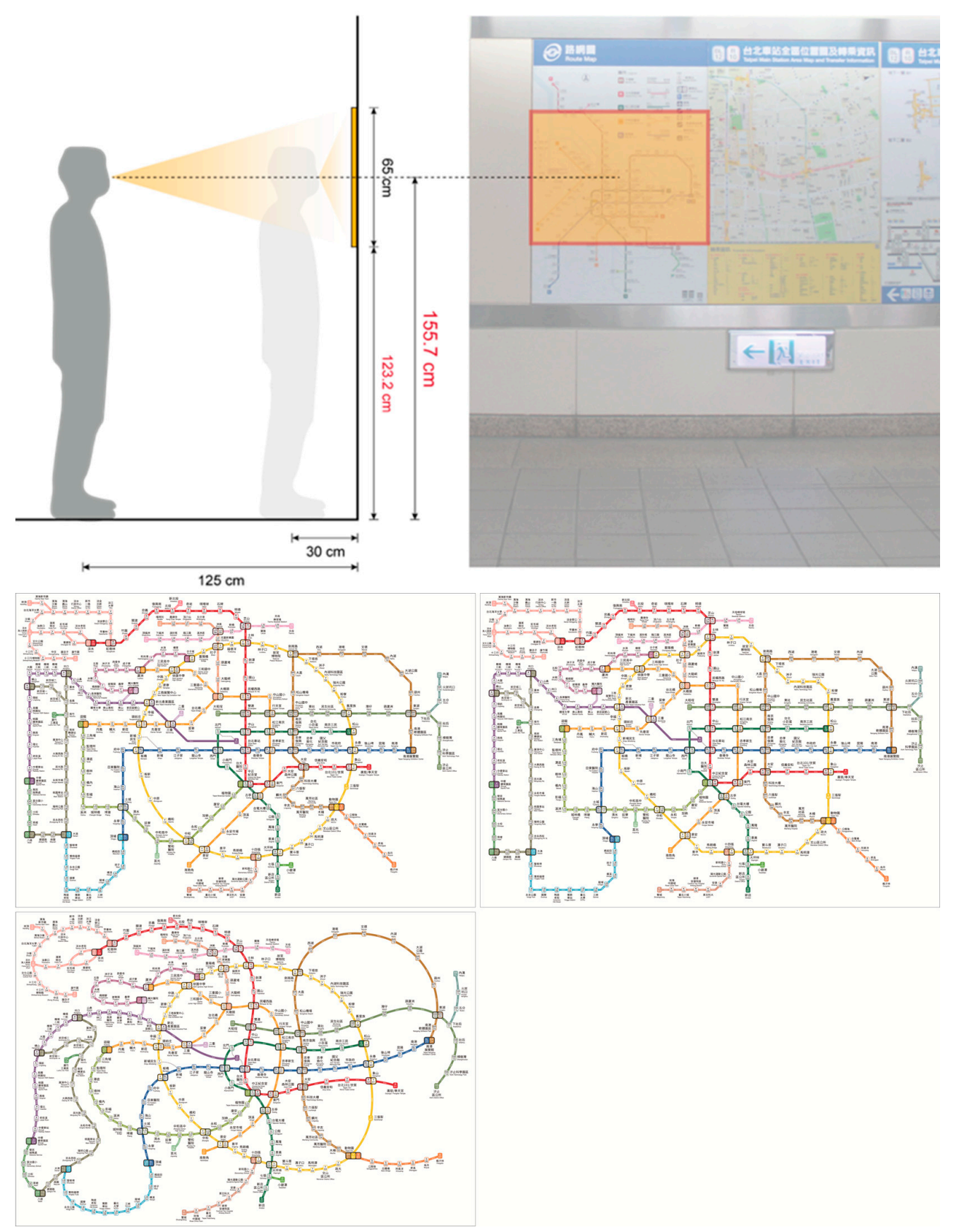

Figure 3. New route maps design.

\section{Results}

\subsection{Results on Cognitive Mapping}

The participants' drawing order was recorded on video. We found that $68.8 \%$ of the participants drew metro routes first before drawing specific points (e.g., stations, transfer stations, or terminal stations) and annotated station names before extending other routes from a transfer station. Notably, all the participants drew the horizontally oriented Blue line first, the vertically oriented Red line next, and then other routes. The first station drawn by $46.9 \%$ of the participants was Taipei Main Station where the Blue line and Red line intersect 
(Table 1). Taipei Main Station was annotated by 30 of the 32 participants. In fact, according to metro statistics, the Blue line and Red line are the routes in the Taipei Metro with the highest and the second highest ridership, respectively. Thus, Taipei Main Station, being located at the center of the route map and with the highest ridership, was prominently placed in the participants' drawing order. This indicated that for the participants in this cognitive mapping, the location where the horizontal and vertical lines intersected, at Taipei Main Station, was their most familiar and definite knowledge point regarding the route map.

Table 1. Statistical results for drawing order.

\begin{tabular}{ccc}
\hline Item & Total (Persons) & Percentage of Persons (\%) \\
\hline Point-line & 10 & $31.2 \%$ \\
\hline Line-point & 22 & $68.8 \%$ \\
\hline Taipei Main Station as the first station drawn & 15 & $46.9 \%$ \\
\hline
\end{tabular}

Overall, $71.9 \%$ of the participants opted to use rounded corners to depict the turning points of the metro lines. This finding corresponds with that of Nagao et al. [9] who indicated that rounded corners at route turning points are critical for representing route continuation. This finding indicated that rounded corners on a route map facilitated the representation of route extensions; these rounded corners could also be turned into large rounded corners and even curves to represent route orientations to support a person's cognitive memory. Three types of compositions were identified based on participants' drawing of lines and turning points on a route map: straight lines and corners (SCs), straight lines and rounded corners (SRs), and curved and rounded corners (CRs). Most participants used CRs for representations on the cognitive map. Among the participants using SCs, SRs, and CRs, a significant difference was observed between drawing points first and drawing lines first $(p=0.015[<0.05])$. Those using SCs all drew lines first and points next; a third of those using SRs drew lines first and points next; half of those using CRs drew lines first and points next (Table 2).

Table 2. Percentage of participants using each composition type in cognitive mapping.

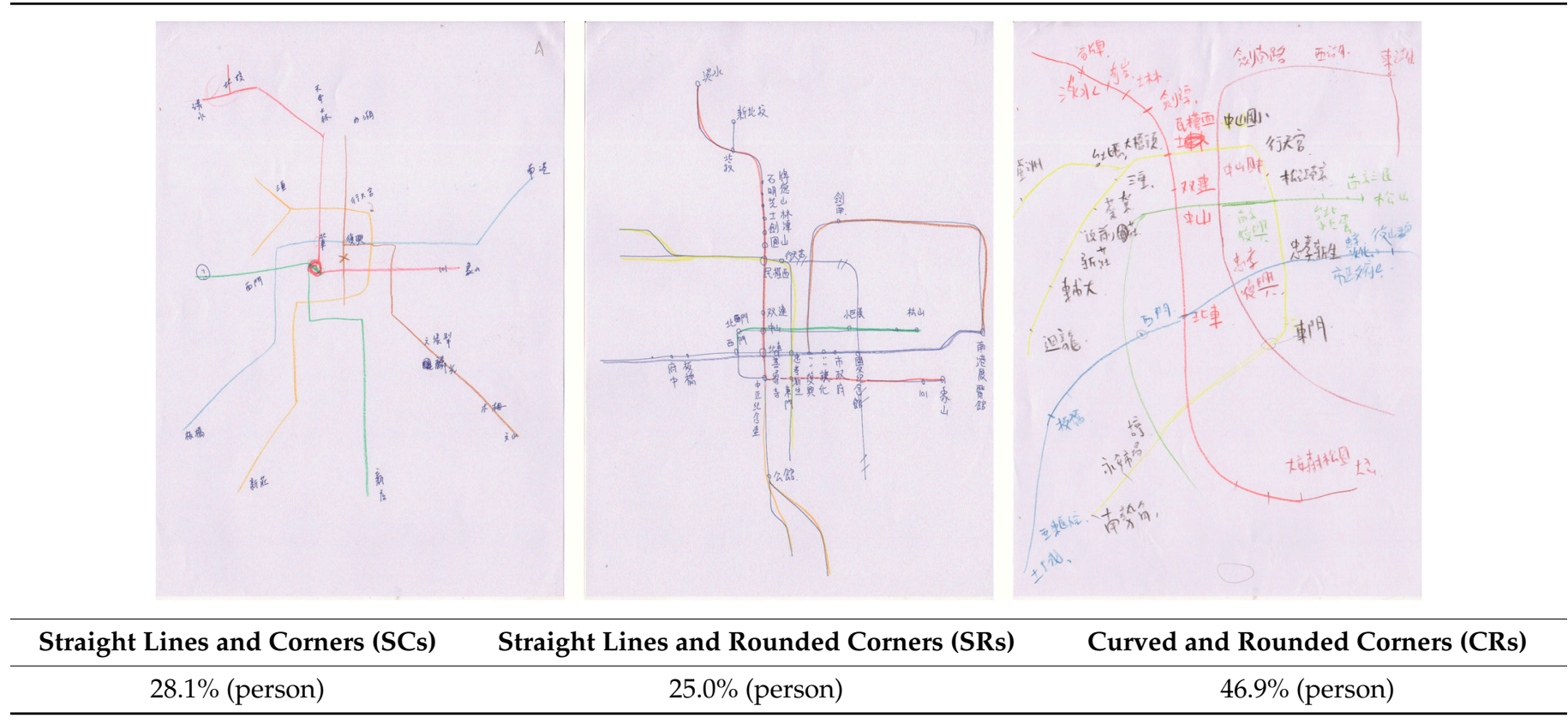


The following elements used by the participants when drawing a cognitive route map were assessed: use of color, use of transfer stations, use of terminal stations, and use of graphics; these elements were used to facilitate memorization when representing information on the drawing. The results are summarized in Table 3.

Table 3. Statistical results on the most frequently used elements in drawing a route map based on cognitive mapping.

\begin{tabular}{ccc}
\hline Item & Persons & Percentage of Participant (\%) \\
\hline $\begin{array}{c}\text { Using color } \\
\text { Using the five correct colors (one for each } \\
\text { metro line) }\end{array}$ & 29 & $90.6 \%$ \\
\hline Using transfer stations & 22 & $68.8 \%$ \\
Accuracy rate over 50\% & 31 & $96.9 \%$ \\
\hline Using terminal stations & 16 & $50.0 \%$ \\
Accuracy rate over 50\% & 30 & $93.8 \%$ \\
\hline Using graphic features of route forms & 20 & $62.5 \%$ \\
\hline Using transfer stations on branch lines & 29 & $90.6 \%$ \\
\hline Using routes beyond the system & 18 & $56.3 \%$ \\
\hline Using landmarks or bodies of water & 9 & $28.1 \%$ \\
\hline
\end{tabular}

In drawing the cognitive route map, $90.6 \%$ of the participants used colors to facilitate memorization; $68.8 \%$ of these participants used the five correct colors to draw the five main routes. The number of women using colors was significantly higher than that of men using colors $(p=0.003[<0.05])$, indicating that color was among the factors related to participants' memory of the route map. We found that among the elements used by the participants, transfer stations, terminal stations, and features of route forms were widely used. Overall, $96.9 \%$ of the participants drew transfer stations, and $93.8 \%$ drew terminal stations. The percentage of those who drew transfer stations was significantly correlated with the participants' metro usage experience $(p=0.0016[<0.05])$ (Table 3). Participants taking the metro more frequently drew more transfer stations, and those who drew more transfer stations also drew more terminal stations $\left(r=0.74{ }^{* *}\right.$, strong correlation). The participants who drew lines first and points next annotated more transfer stations than did those who drew points first and lines next $(p=0.0418)$.

This finding indicated that transfer and terminal stations were crucial elements in the cognitive route maps in the participants' minds, in the drawing process. Most participants tended to annotate a transfer station before adding details on the cognitive route map of an area. Regarding participants' rate of drawing transfer stations, we found that it was the highest for Taipei Main Station and then tended to decrease with distance from this main transit station (Table 4).

Participants' cognitive memory of terminal stations was relatively similar. The results revealed that most participants were influenced by the distribution and locations of these stations on the map drawing. For example, Tamsui metro station, which was located on the top of the vertical orientation, and Taipei Nangang Exhibition Center metro station, which was located at the far right of the drawing and had memorization graphics, were the most frequently drawn terminal stations (Table 5). 
Table 4. Frequency and distribution of transfer stations as a drawing element.

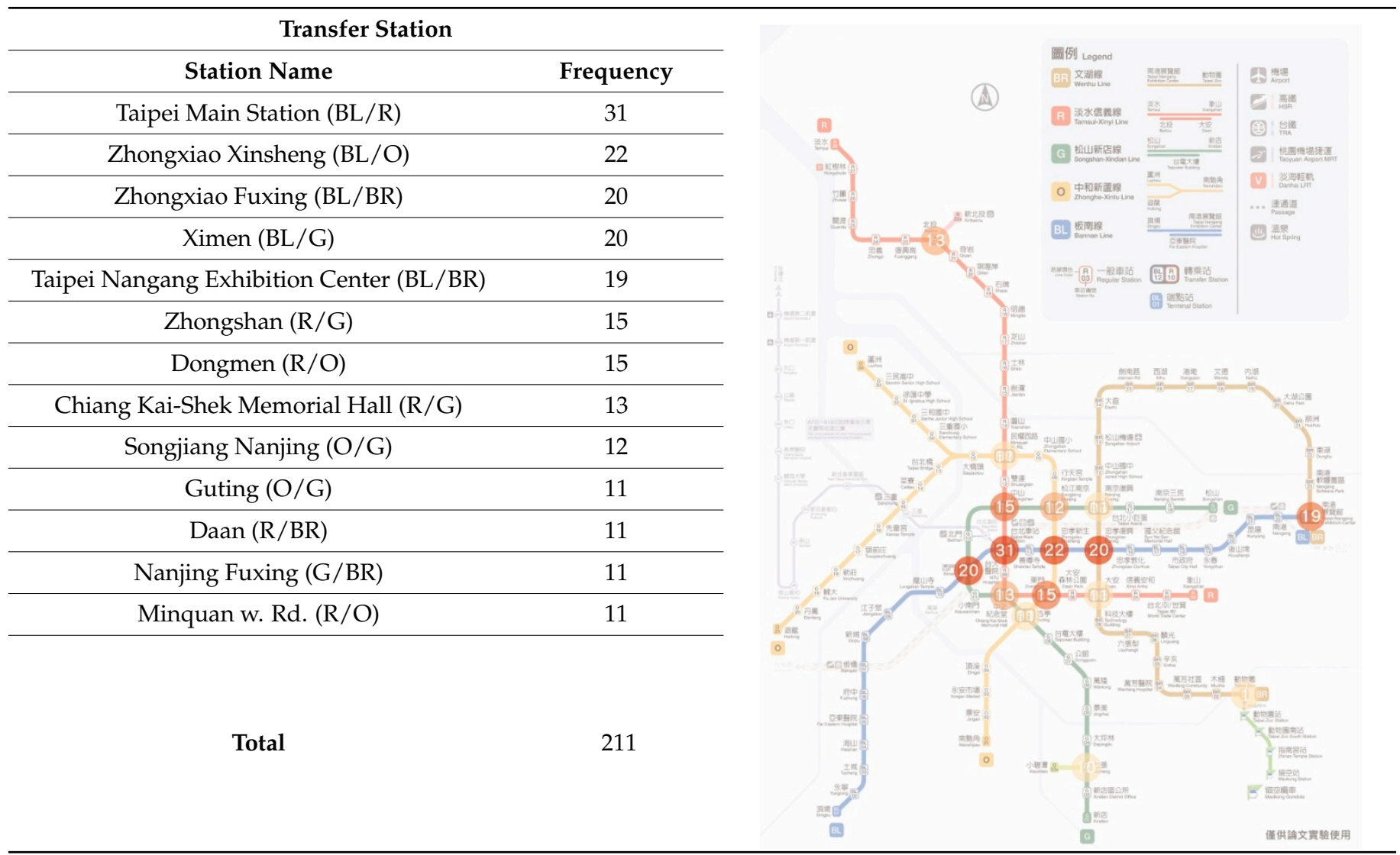

Table 5. Frequency and distribution of terminal stations as a drawing element.

\begin{tabular}{cc}
\hline Transfer Station & \\
\hline Station Name & Frequency \\
\hline Tamsui (R) & 27 \\
\hline Taipei Nangang Exhibition Center (BL) & 27 \\
\hline Taipei Nangang Exhibition Center (BR) & 21 \\
\hline Taipei Zoo (BR) & 20 \\
\hline Xiangshan (R) & 19 \\
\hline Nanshijiao (O) & 18 \\
\hline Songshan (G) & 17 \\
\hline Xindian (G) & 16 \\
\hline Luzhou (O) & 14 \\
\hline Huilong (O) & 9 \\
\hline Dingpu (BL)
\end{tabular}

Total 199
10

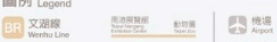

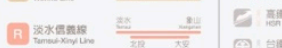

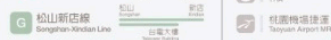

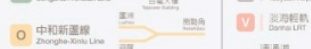

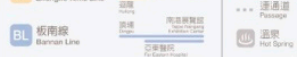

$=-190$

중

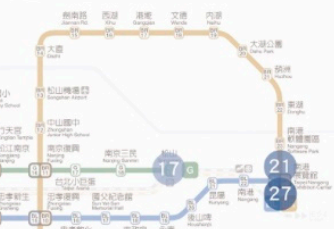


In total, $90.6 \%$ of the participants used at least one type of graphic to facilitate memory as they drew the routes. Most participants stated that they could memorize clearly the graphics formed by the routes on the map, such as the square shape formed by the Brown line in the upper right and the forked shape of the route to the left of the drawing, which ended in two terminal stations. The results revealed that $75 \%$ of the participants drew an obvious square shape (A) in figure $\mathrm{X}$ in the upper right of the drawing, and $68.8 \%$ of the participants drew a forked shape (B) in figure $X$ to the left of the drawing. A few participants drew the shape of the central part (C) in figure $\mathrm{X}$ and a triangular shape (D), accounting for $12.5 \%$ and $6.3 \%$ of all drawings, respectively (Figure 4 ).

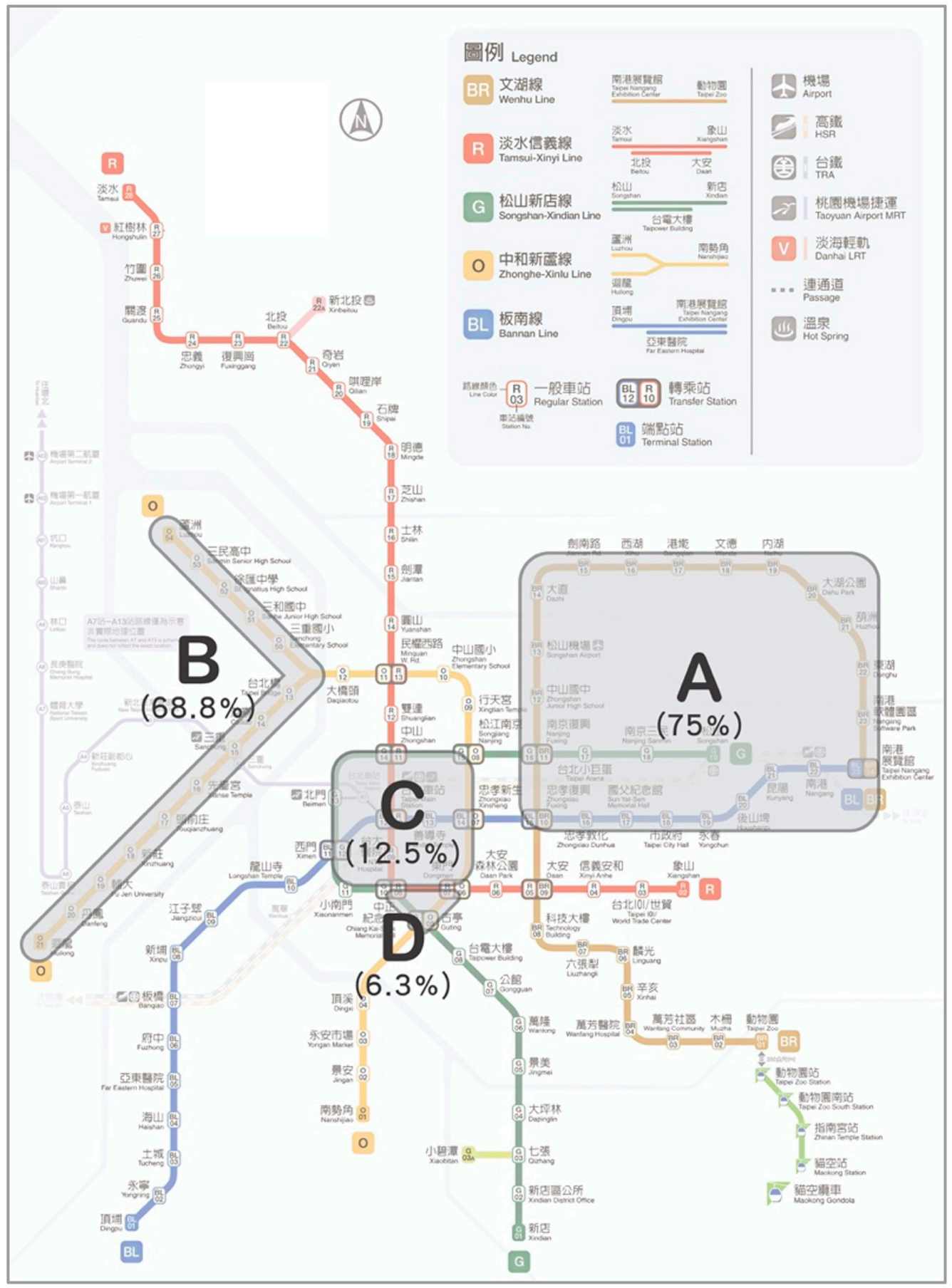

Figure 4. Graphic memory usage percentage in terms of drawing elements. 
As the participants were drawing the cognitive route map, we found that the participants were often uncertain about whether the routes involved turning points, as indicated by observations such as "in my memory, this route leads to the lower left corner," "this should be straight," and "I remember there was a turning point here." Some participants stated that they particularly remembered the turning points of routes or intersections involving transfer stations.

In summary, we found that most of the participants first drew routes and then stations, and almost all the participants designated routes using various colors. In the participants' cognitive mapping, they employed three types of route composition, namely SCs, SRs, or $\mathrm{CRs}$, to represent the graphic features of the routes, and they annotated transfer stations and terminal stations. Regarding the participants' route map drawing order, they drew graphics of routes and areas first, followed by annotation of transfer stations at route intersections as well as the start and terminal stations of the routes (Table 6). Although they were not statistically significant, we will be comparing the subsequent three map proposals in particular.

Table 6. Cross comparison of drawing approach and drawing elements.

\begin{tabular}{cccc}
\hline Element/Drawing Approach & $\begin{array}{c}\text { Straight Lines and Corner } \\
\text { (SC) }\end{array}$ & $\begin{array}{c}\text { Straight Lines and } \\
\text { Rounded Corner (SR) }\end{array}$ & $\begin{array}{c}\text { Curved and Rounded Corner } \\
\text { (CR) }\end{array}$ \\
\hline Color use percentage & $80 \%$ (of the participants) & $85.7 \%$ (of the participants) & $100 \%$ (of the participants) \\
\hline Mean transfer stations used & 6 (persons) & 6.3 (persons) & 7.1 (persons) \\
\hline Mean terminal stations used & 4.6 (persons) & 6 (persons) & 5.5 (persons) \\
\hline Mean memorization shapes used & 1.4 (persons) & 2 (persons) & 1.6 (persons) \\
\hline
\end{tabular}

A metro route map was gradually constructed with points, lines, and areas. Greater metro usage experience enabled participants to draw more transfer and terminal stations. Taipei Main Station was not only the station most frequently annotated but also the station typically annotated first. At route turning points, $68.8 \%$ of the participants opted to use rounded corners to represent the turning, revealing that the rounded corners on the route map facilitated route representation and supported the participants' cognitive memorization (Figure 4).

\subsection{Results on Route Tasks}

We referenced the basic elements of route map composition proposed by Nagao et al. [15]; thus, stations, routes, and transfer station served as the items for classification. Based on the model of route description and analysis of Brosset [20], we coded the elements of composition to facilitate the conversion of the routes planned by the participants into a visualized route planning model. We employed two types of route tasks: (1) route planning with designated start and end stations and (2) route planning with designated start and end stations with the requirement of passing three designated stations on the way. Each type of route task involved three subtasks; the participants were instructed to plan the route that they considered the fastest (routes with the fewest transfers or stops). We want to understand how users base their route planning on distance, travel time, or the number of transfers between different distances' start and end station.

(1) Route planning task with designated start and end stations

In Tasks Q1, Q3, and Q5, the participants were instructed to plan routes with designated start and end stations. Task Q1 required two transfers; for the first transfer, three transfer stations were available for selection, and for the second transfer, only one transfer station was available. Task Q3 required one transfer, and two transfer stations were available for selection. Task Q5 required one transfer, and only one transfer station was available. The experimental results indicated that in more complex tasks, the participants spent more time on planning. Although all the participants planned routes with the fewest 
transfers in Tasks Q1, Q3, and Q5, only in Task Q5, with the simplest route, did all the participants plan routes with the fewest stops. In Task Q3, 81.25\% of the participants used routes with the fewest stops, whereas in Task Q1, only $34.38 \%$ of the participants employed this approach; notably, some participants exhibited large deviations from the average. This indicated that a larger number of necessary transfers and transfer station options resulted in a lower percentage of the participants being capable of planning routes with the fewest stops. In the current route map, using multiple transfers was challenging. Regarding transfer station options, the last available transfer station tended to be selected for transfer (56\% of the participants in Task Q1; 81\% of the participants in Task Q3). The participants tended to select transfer stations closer to the end station (Figure 5).

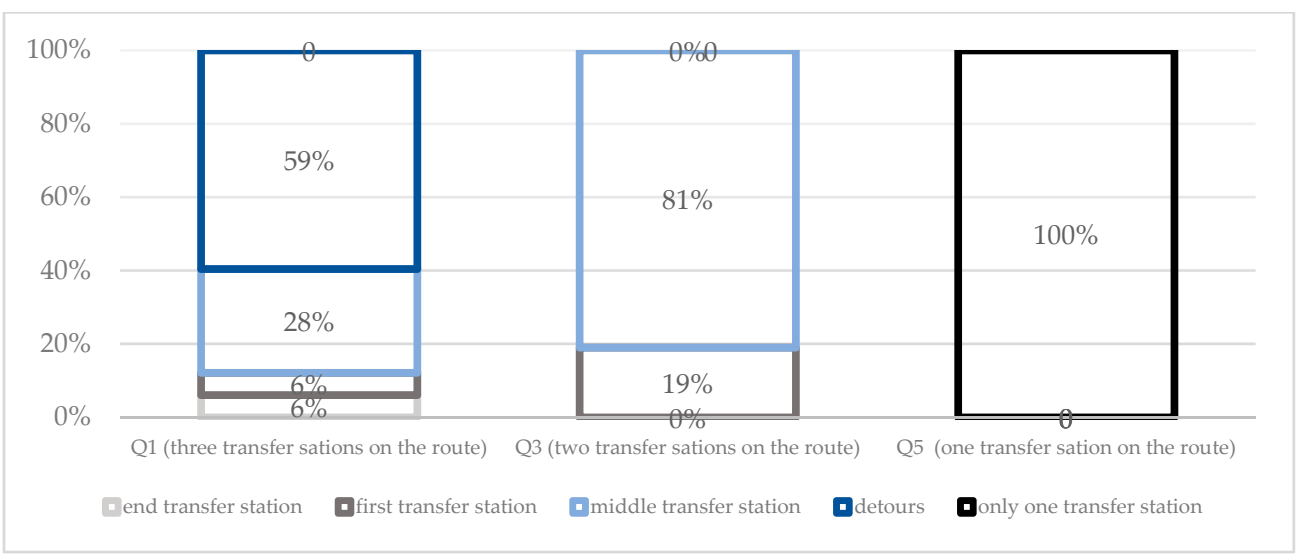

Figure 5. Locations of the selected transfer stations.

(2) Route planning tasks with designated start and end stations and the requirement of passing three designated stations (Q2, Q4, and Q6)

In Tasks Q2, Q4, and Q6, the participants could decide the order in which they pass the three required stations. Thus, in addition to considering the start and end stations, the route planning involved simultaneously considering the locations of five stations. The starting point in Task Q2 was the southernmost of all tasks. Among the five stations, the distance between the southernmost and northernmost stations was much longer than that between the easternmost and westernmost stations. Therefore, the participants had to focus on vertical routes. The results indicated that $53 \%$ of the participants chose the southernmost station as their start station and moved northward before returning to the end station in the center. The starting point in Task Q4 was the westernmost. The distance between the easternmost and westernmost stations was much longer than that between the southernmost and the northernmost stations. Thus, the journey involved more horizontal routes. The results indicated that $72 \%$ of the participants opted to start from the westernmost station and move toward stations to the east before returning to the end station in the center. In Task Q6, the distance between the easternmost and westernmost stations was only slightly longer than that between the southernmost and northernmost stations. The results revealed that $50 \%$ of the participants opted to start from the easternmost station and move westward. Because the participants planned routes according to the locations of the given five stations, most of them planned their routes according to the distances of these locations to avoid detours. In this manner, more efficient routes were planned, the number of stops passed generally decreased, and the time required was shorter.

In addition to avoiding detours, another factor in planning was the number of transfers. For example, in Task Q4 between the Nanjing Fuxing and Taipei Nangang Exhibition Center stations (Figure 6), one additional transfer was required when $60 \%$ of the participants opted to detour downward; $40 \%$ of the participants chose to detour upward, requiring no transfer, but they had to pass four additional stations. Convenient transfer was the greatest consideration for the few participants with less experience of using the metro who rather 
detoured; this finding indicated that route planning that reduces detours and the number of transfers was important for route map readers (Table 7). Although route maps based on topology mainly represented relationships between stations and routes, geographic locations were not depicted accurately. Route maps were not to scale, but the location of each station marked on them remains the basis for map readers in determining to detour or not.

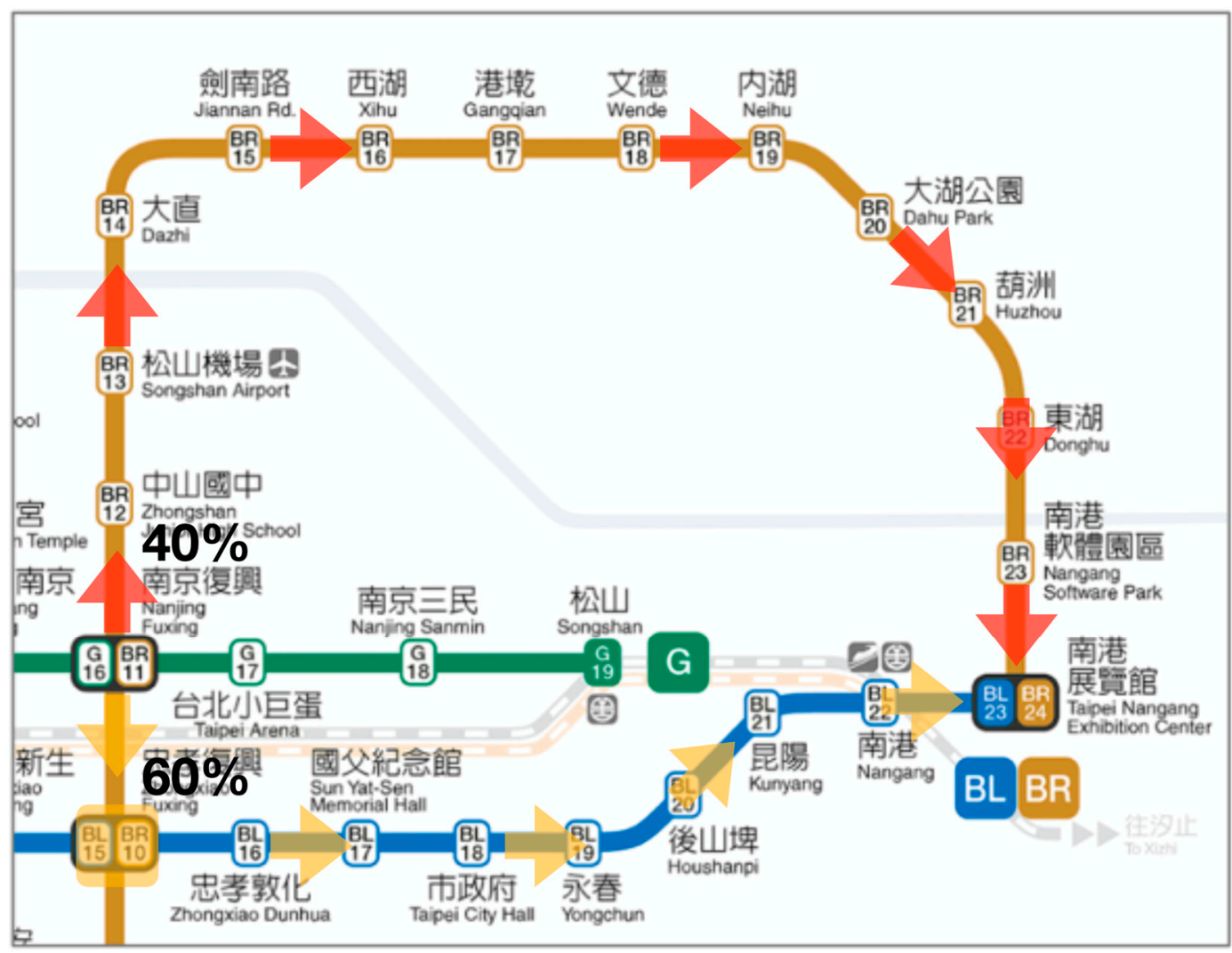

Figure 6. Overall, $60 \%$ of the participants opted to detour downward, which required an additional transfer, whereas $40 \%$ of the participants chose to detour upward and had to pass four additional stations.

The responses to Q1 to Q6 revealed that in planning routes, the participants attempted to minimize as much as possible the estimated time required by their route of choice. Visualization analysis conducted based on a route planning model revealed the following patterns in the participants' route selections:

1. Avoiding station that involves a change of traveling direction in the selected route.

2. Decreasing the number of transfers along the selected route.

3. Selecting transfer stations closer to the end station.

4. Selecting movement directions from the top to the bottom or from the left to the right in the drawing and avoiding the complex central area.

Since the Taipei MRT route map has been widely used, the 32 participants in Experiment 1 were divided into four groups according to their metro usage experience and frequency using cluster analysis: low experience and infrequent use, low experience and frequent use, high experience and infrequent use, and high experience and frequent use. The findings revealed that as the participants' experience of taking the metro decreased, the time spent on route search and planning increased. As the level of experience increased, although the speed of route search and planning increased, the participants easily misidentified stations and consequently gave wrong answers. Analysis of the results for "total time for answering," "accuracy rate of search task," and "error in estimated travel time" indicated no significant correlations among the four groups (Table 7). 
Table 7. Cluster analysis based on participants' experience.

\begin{tabular}{cccccccccc}
\hline Group & $\begin{array}{c}\text { Percentage } \\
\text { of Persons }\end{array}$ & $\begin{array}{c}\text { Usage } \\
\text { Experience }\end{array}$ & $\begin{array}{c}\text { Times of } \\
\text { Use per } \\
\text { Week }\end{array}$ & $\begin{array}{c}\text { Shortest } \\
\text { Time for } \\
\text { Transfer } \\
\text { Search }\end{array}$ & $\begin{array}{c}\text { Longest } \\
\text { Time for } \\
\text { Transfer } \\
\text { Search }\end{array}$ & $\begin{array}{c}\text { Average Time } \\
\text { to Complete } \\
\text { Planning Task }\end{array}$ & $\begin{array}{c}\text { Total Time } \\
\text { for } \\
\text { Answering }\end{array}$ & $\begin{array}{c}\text { Accuracy } \\
\text { Rate of } \\
\text { Search } \\
\text { Task }\end{array}$ & $\begin{array}{c}\text { Error in } \\
\text { Estimated } \\
\text { Travel } \\
\text { Time }\end{array}$ \\
\hline LSIU & $9.4 \%$ & $1.3 \mathrm{y}$ & $1.2 \mathrm{t}$ & $218 \mathrm{~s}$ & $375.3 \mathrm{~s}$ & $182.0 \mathrm{~s}$ & $1139.3 \mathrm{~s}$ & $100 \%$ & $\pm 55.4 \%$ \\
\hline LSFU & $34.4 \%$ & $0.9 \mathrm{y}$ & $5.3 \mathrm{t}$ & $230.8 \mathrm{~s}$ & $310.9 \mathrm{~s}$ & $166.0 \mathrm{~s}$ & $1039.8 \mathrm{~s}$ & $69.7 \%$ & $\pm 27.6 \%$ \\
\hline HSIU & $28.1 \%$ & $8.4 \mathrm{y}$ & $2.9 \mathrm{t}$ & $200.4 \mathrm{~s}$ & $281.7 \mathrm{~s}$ & $170.9 \mathrm{~s}$ & $994.8 \mathrm{~s}$ & $72.2 \%$ & $\pm 32.0 \%$ \\
\hline HSFU & $28.1 \%$ & $8.4 \mathrm{y}$ & $6.2 \mathrm{t}$ & $219.6 \mathrm{~s}$ & $329.3 \mathrm{~s}$ & $139.6 \mathrm{~s}$ & $967.6 \mathrm{~s}$ & $79.6 \%$ & $\pm 34.4 \%$ \\
\hline
\end{tabular}

LSIU, low experience and infrequent use; LSFU, low experience and frequent use; HSIU, high experience and infrequent use; HSFY, high experience and frequent use.

3.2.1. Experiment 1 Revealed the following Similarities in Most Participants' Cognitive Memory Regarding Route Map Structure:

Users tended to take Taipei Main Station as the fixed cognitive center. Using the reference structure of cognitive maps proposed by Hart (1979), we noted that most users tended to take Taipei Main Station as the fixed center of their spatial cognition memory when reading the current Metro Taipei Route Map. In a structure emphasizing the intersections of the horizontal Blue line and the vertical Red line, users further completed cognitive mapping for the route map by egocentrically referring to their experience regarding transfer and terminal stations.

Routes in the form of gestalt facilitated cognitive memory. Among the elements for drawing a cognitive route map, in addition to basic colors, transfer stations, and terminal stations, graphic memory formed through route shapes and bifurcations of routes on the route map helped to enhance users' cognitive memory.

Users planned routes with consideration of the number of stations they must pass, and the transfers required. Based on the destination, the participants made plans that avoided detours; they typically planned their routes from near to far or from far to near the starting point before considering the number of transfers to modify the route choice. Even though route maps are not to scale, map readers still make plans according to the locations of stations on a route map (Figure 7).

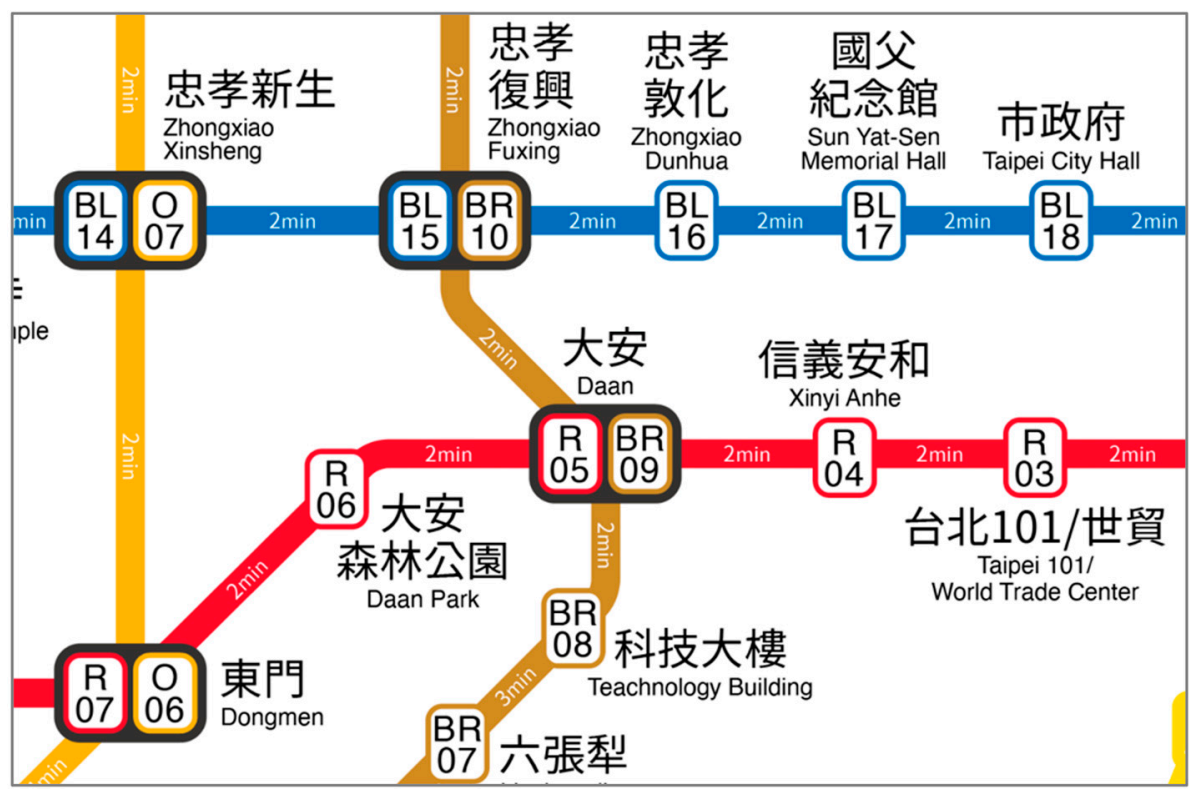

Figure 7. Considering the number of transfers to avoid detours. 
The usability of the current octilinear route map was rated as D. The UMUX evaluation score references a formula proposed by Berkman and Karahoca (2016) and converts the score into one similar to the System Usability Scale score for verification. The study revealed that most users rated the usability of the current route map as low, with a score of 69.7, indicating that they were barely satisfied with this route map and thought that space remained for improvement.

Users held a positive and supportive attitude toward integrating travel time information. According to the interview questionnaire results, $78.1 \%$ of the participants agreed with the notion of integrating travel time information. The participants stated that they required such time information when using a route map and believed that annotating travel time information would have a positive effect on route planning.

Although studies indicate that the temporal distance is not the best way of performance [21], it is necessary to add time to the map according to users' opinions. In certain situations, such as when people want to go to another spot before they catch a plane, a time-marked map may help them keep track of their time. People who commute every day may have less need for a time-marked map. We posit that route maps composed of curves may enhance the outcomes of users' cognitive memory while also increasing the possibility of graphic memory use. The cognitive memory-related performance of CRs and SRs in the drawing approach indicated that the use of curves to replace nodes generated by turns along conventional octilinear routes may reduce the number of nodes and might effectively reduce the load on users' memory.

\subsubsection{Experiment 2: Comparison and Evaluation of New Route Map Designs}

Roberts et al. [14] refuted the view that the conventional octilinear system was the absolute gold standard for route maps. This study considered future plans for building new metro lines and proposed three route map designs that employ distinct compositions. The horizontal layout was used to ensure that new routes could be incorporated in the future; its length was set as $95.3 \mathrm{~cm}$ and its width as $65 \mathrm{~cm}$, and the maps were made to scale. To ensure that route composition was not affected by other variables, all three design proposals included time annotation.

Route map A (Proposal A): Route map A was based on a hybrid system. It was an integration of the conventional octilinear and the curve drawing approaches; the Circular line (indicated in yellow) served as the main connecting framework for all the routes. Taipei Main Station was the central point of the drawing, and the Circular line was in a perfect circle. The form of the original route map was preserved in the layouts of other routes, and the distance between two transfer stations were evenly spaced (Figure 8).

Route map B (Proposal B): For route map B, the conventional octilinear system was employed. The horizontal Blue line and the vertical Red line served as the primary framework for connections, and the stations were distributed along each route as evenly as possible. To equally distribute the stations to the left and right of Taipei Main Station, the composition of the Circular line (indicated in yellow) was revised into a layout whose center was to the middle right (Figure 9).

Route map C (Proposal C): Route map C employed an all-curve system. This map was generated based on the route layouts of Proposals A and B; the straight lines in the octilinear design were entirely replaced by curves. We used the Bézier curve function in imaging software to transform each route into a smooth state with the fewest anchor points. Despite the use of curves to draw the route map, the relative positions of the stations were preserved (Figure 10). 


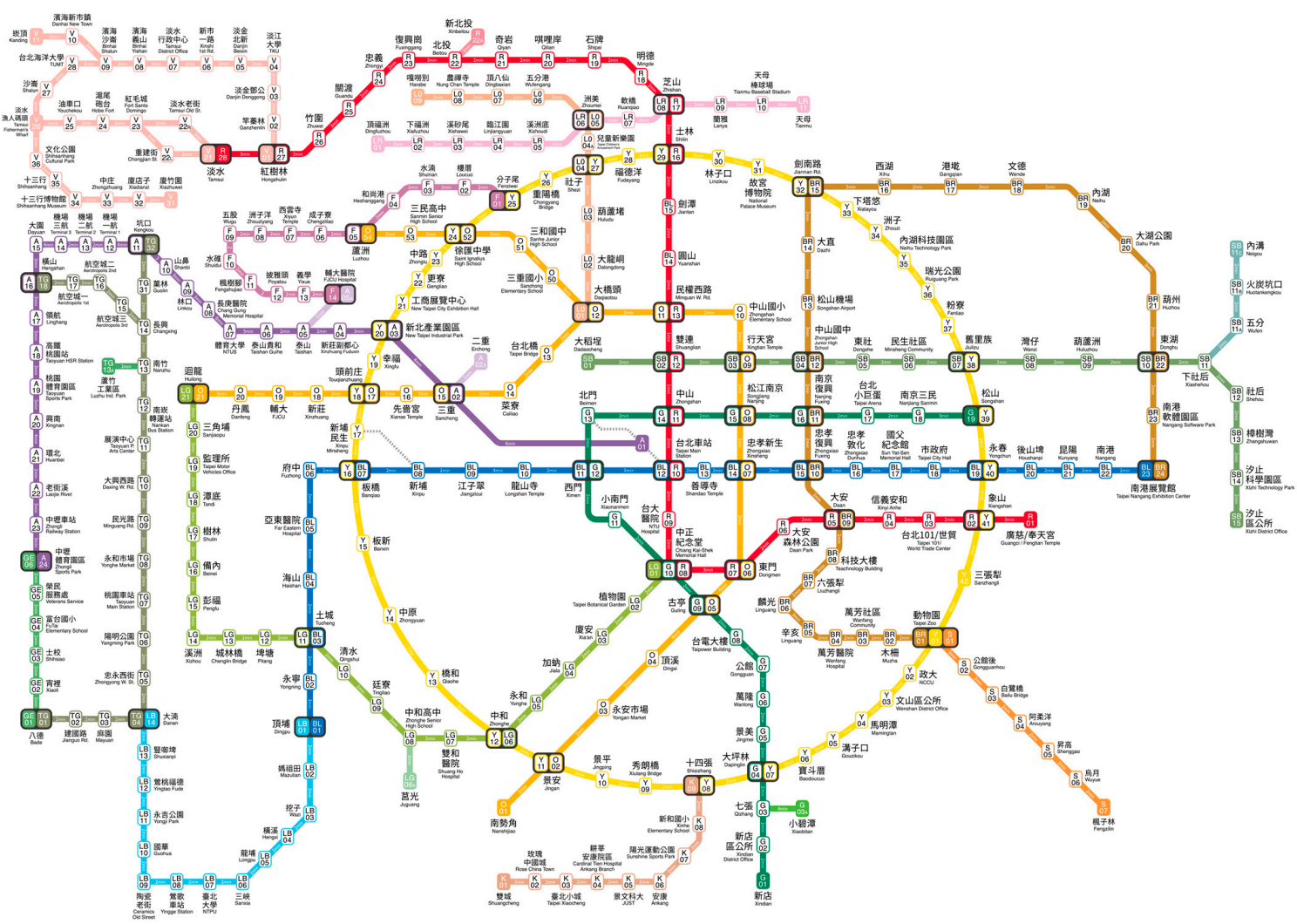

Figure 8. Route map A.

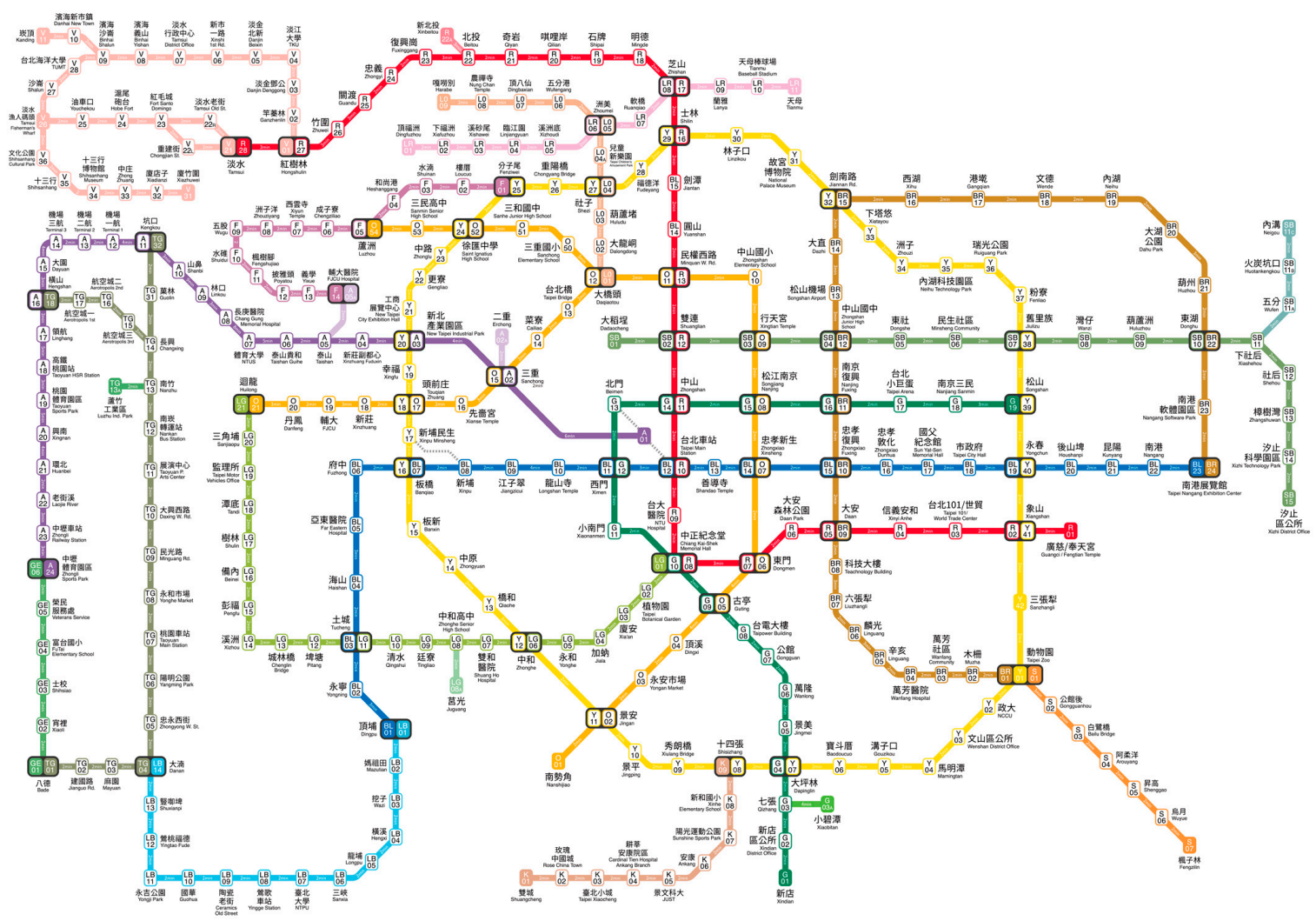

Figure 9. Route map B. 


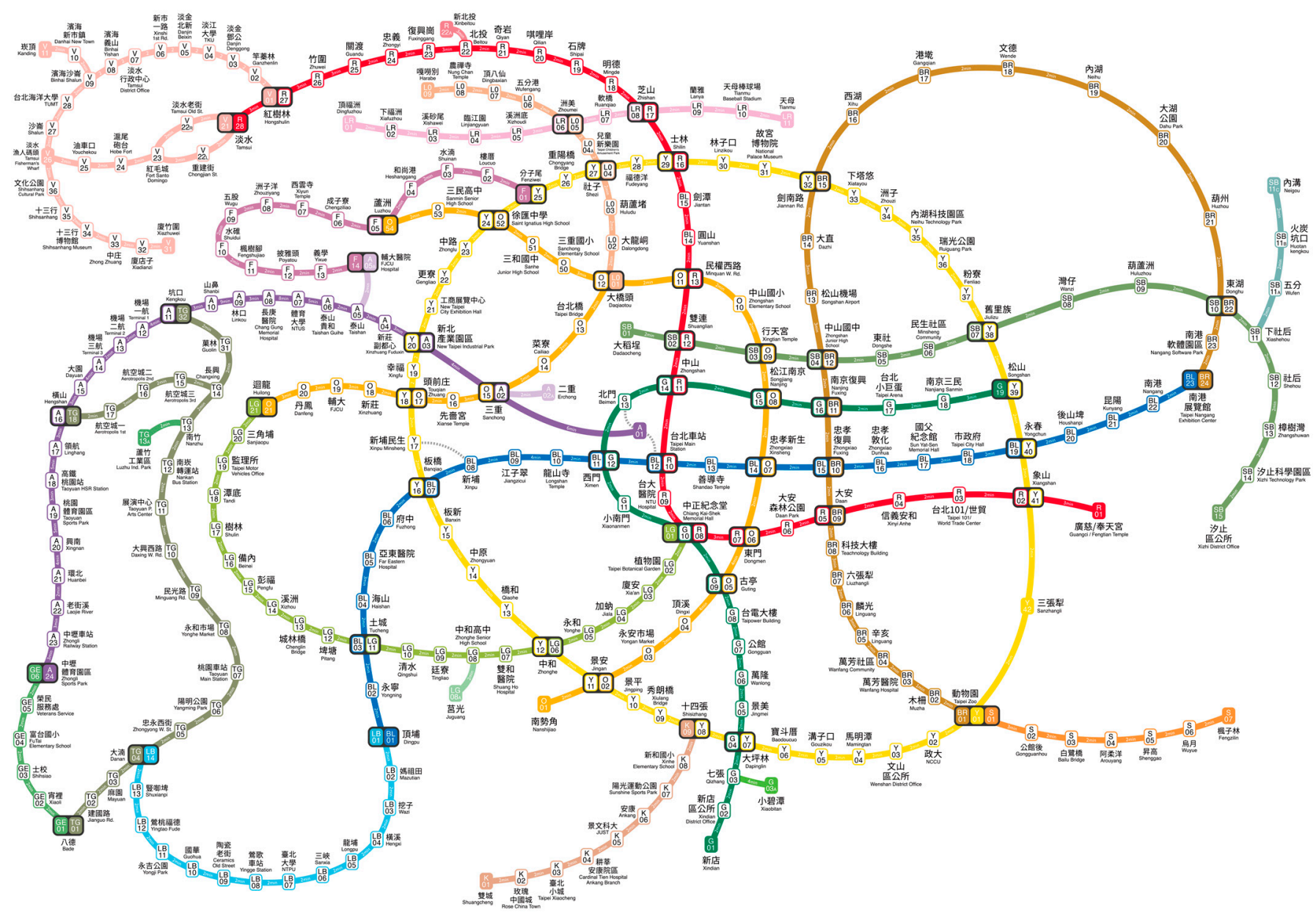

Figure 10. Route map C.

In Experiment 2, the usability of the three proposed route map designs (that employ the aforementioned three compositions) were compared through usage experience, cognitive mapping, route tasks, a route planning model, and an evaluation scale. The four route planning tasks with designated start and end stations on different route maps were as follows (Table 8):

Q1: Long-distance route planning with the start and end points diagonally located on the drawing.

Q2: Short-distance route planning with the start and end points diagonally located on the drawing.

Q3: Route planning where the distance between the start and end points was the longest.

Q4: Route planning where the distance between the start and end points was short and the end station was located on the Circular line. 
Table 8. Four route planning tasks with designated start and end stations on different route maps.

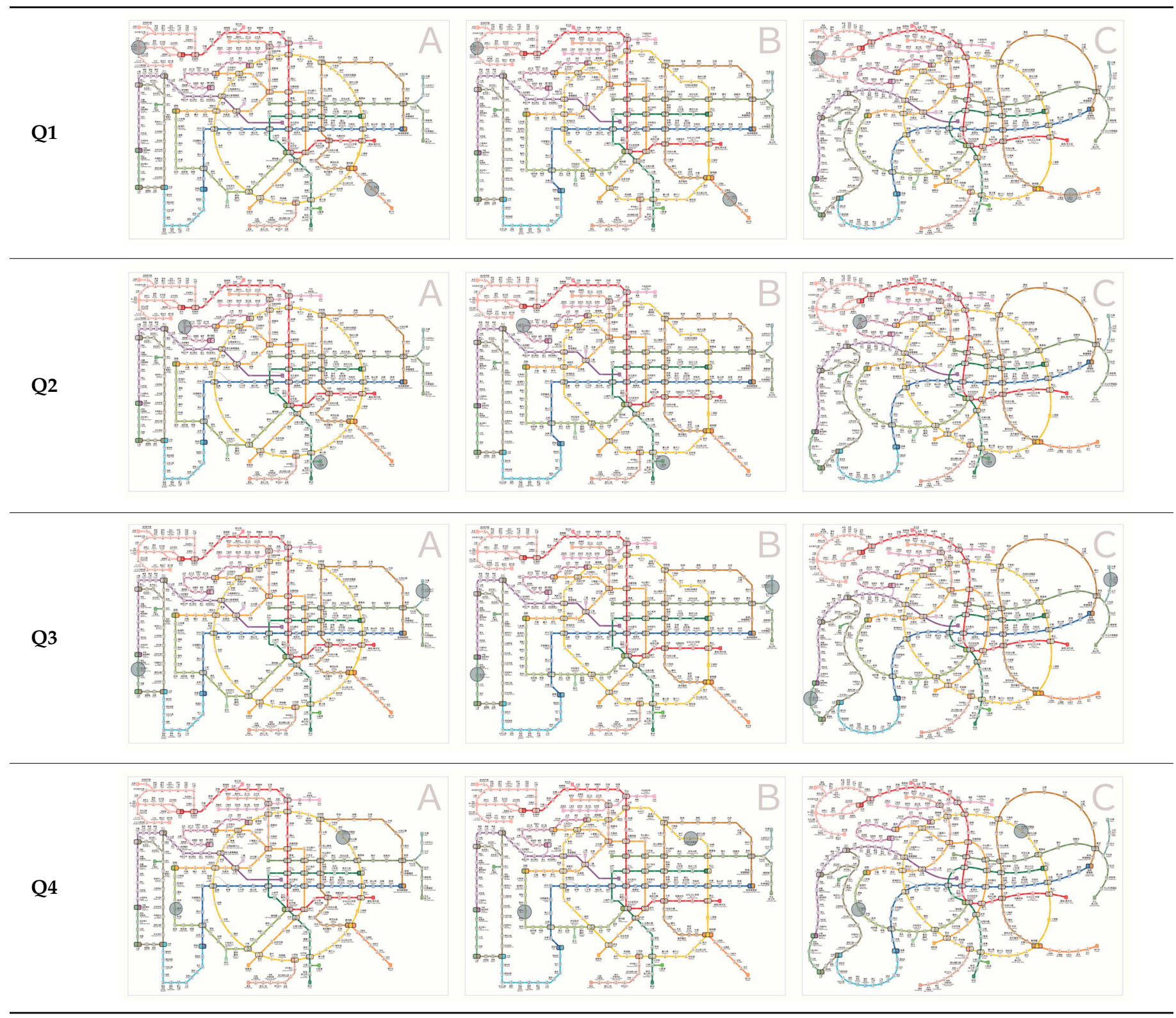

\section{Discussion}

Although the results of the cognitive mapping-based route map were affected by users' usage experience of the metro, experience of using Taipei's metro system did not result in significant differences in the time required for planning route maps.

We compared the participants' performance during each task's cognitive mapping in terms of errors in transfer station, node, and angle. The findings revealed an error of \pm 0.5 transfer station when the hybrid system-based Proposal A was used, which was more favorable than when Proposal B or Proposal C (each with an error of almost 1 transfer station) was used. Proposal A aided users' memorization of transfer stations along routes. However, node errors differed considerably between the proposed maps. More node errors occurred in the use of Proposals A and B, which employed the conventional octilinear system, with the highest number of errors noted for Proposal B ( \pm 4.0$)$. By contrast, Proposal $\mathrm{C}$, which was based on the all-curve system, resulted in the optimal performance in terms of node error and angle error between the start and end stations in the cognitive map. The experiment revealed that the number of nodes drawn by the participants between 
routes affected the locations of transfer stations and angles of the start and end stations in their cognitive route maps. For example, when Proposal B was used, the cognitive load generated when the participants memorized the number of nodes increased the number of errors in transfer stations and angles when the routes were drawn (Table 9).

Table 9. Experiment 2 Route planning model and cognitive route map comparison.

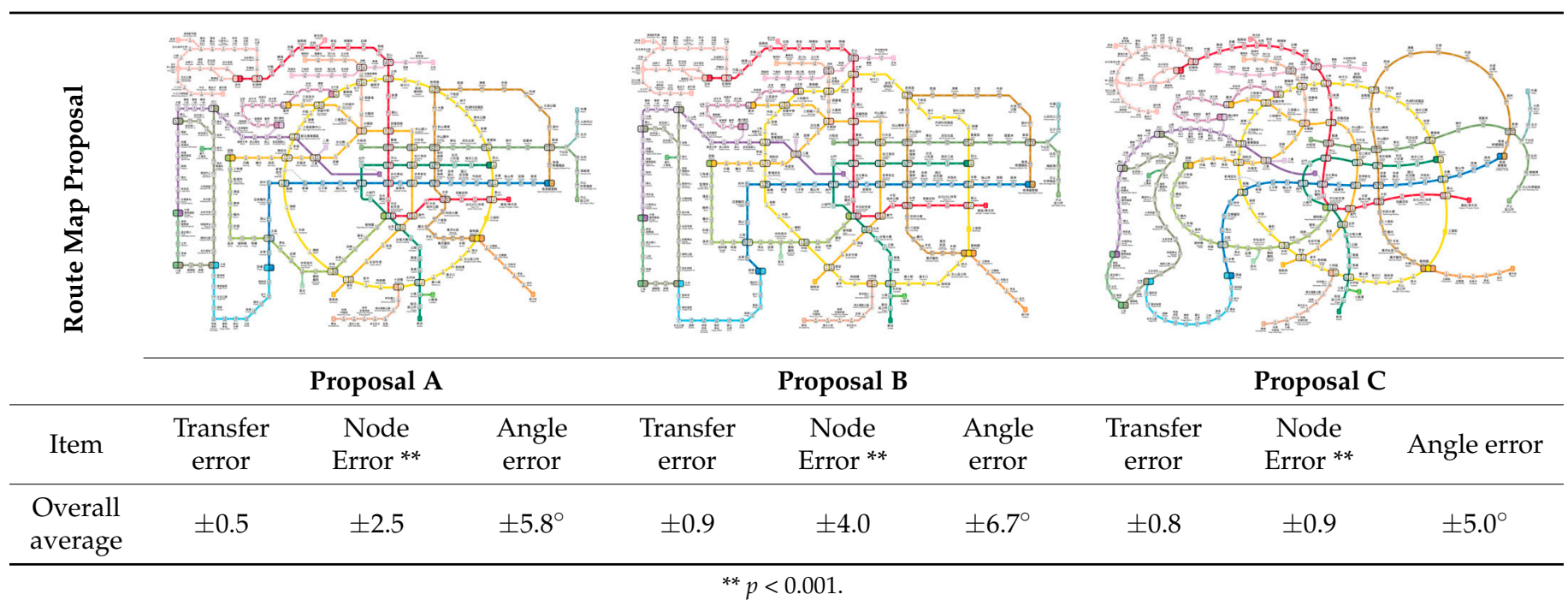

We used one-way analysis of variance to examine the performance of the proposals. We noted no significant difference in transfer error $(\mathrm{F}(2.346)=0.115, p>0.05)$ and angle error $(\mathrm{F}(1.065)=0.359, p>0.05)$ among the proposals. However, the results on node error revealed a significant difference $(F(16.223)=0.000, p<0.05)$, indicating that during cognitive mapping for the three route maps, the number of nodes drawn differed significantly depending on the route map used. Compared with necessary information such as transfer and terminal stations on the route map, the number of nodes changed according to the design of the route map. Comparison of task results and route planning between Proposal B and Proposal C suggested that a high number of nodes compelled users to expend greater effort on memorization. However, the introduction of curves decreased the number of nodes; moreover, in their cognitive memory, the users could concentrate on connections between routes, transfer stations, and terminal stations, effectively reducing cognitive memory errors related to other information.

\section{Route Planning Results of the Three Proposals}

In Task Q1, the greatest difference between Shilin and Taipei Zoo metro stations was the shape of the Circular line and the shape of Brown line between the Daan and Taipei Zoo metro stations. The results indicated that in Proposal B, 60\% of the participants used the Circular line, whereas $40 \%$ of the participants in Proposal A and $40 \%$ of the participants in Proposal C used this line. The Circular line in Proposal B ran straight downward, whereas the Circular line in Proposal A and Proposal C required a detour to the end station, indicating that the drawing style for the Circular line in Proposal B gave the participants an impression of fewer detours. Similarly, the trajectory between Daan and Taipei Zoo metro stations clearly indicated that zigzags in Proposal A gave an impression of a detour. Thus, at the Daan metro station in Proposal A, only half of the participants selected the downward zigzag routes, whereas in Proposal C, all the participants chose downward routes in arcs. This finding indicates that although most route maps were based on topology, most participants attempted to determine the shortest routes to the terminal station rather than making a detour. Moreover, this indicated why the participants' route planning was affected by different representations of the same stations (Figure 11). 


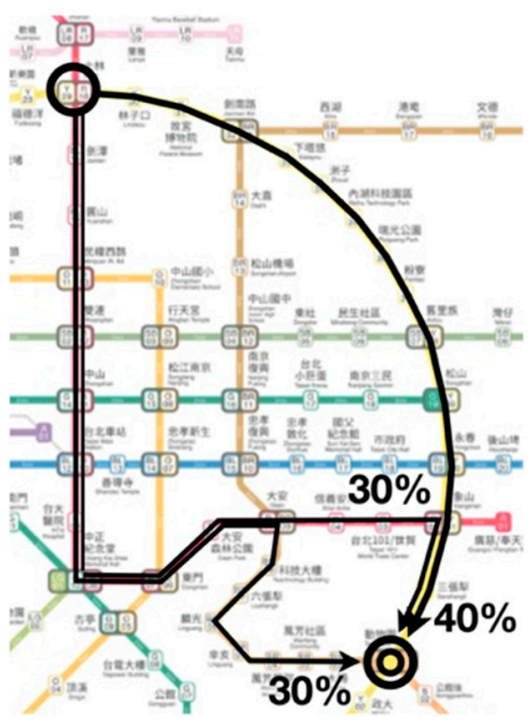

A

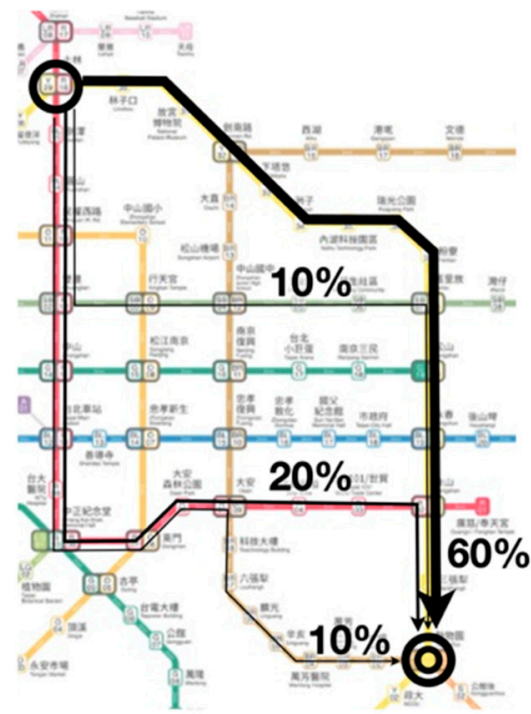

B

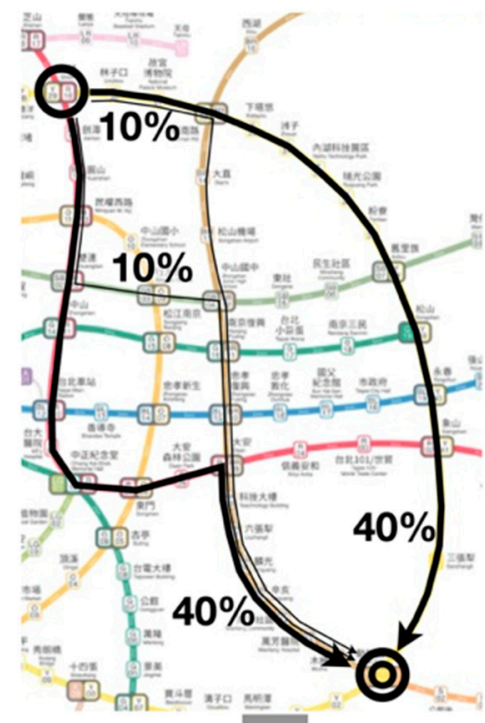

C

Figure 11. Proposal (A-C) showed participants' route planning was affected by different representations of the same start-end stations.

In Task Q2, the 30 participants all opted to transfer at St. Ignatius High School metro station to progress to the end station, Wugu metro station. In this task, the end station could be directly reached using the Circular line, whereas other routes required at least two transfers. The results indicated that among the three proposals, $40 \%, 20 \%$, and $20 \%$ of the participants using Proposal A, B, and C selected the Circular line, respectively. In Proposal A, because of the clear representation of the Circular line, the usage rate of this line was slightly higher than that in other proposals. However, in all the proposals, the results on route planning similarly indicated that even with routes requiring two additional transfers, most participants still tended to adopt a strategy of moving from the start point to the end point (i.e., moving leftward and upward). The Circular line led directly to the destination; however, it involved circling to the right before reaching the end point. Thus, it was considered a detour. In this task, avoiding a detour was regarded by most of participants as more important than several transfers (Figure 12).

Task Q3 was the most complex among the four tasks and required at least four transfers. Given the detour involved in the journey, we found that in Proposal A, 40\% of the participants opted to wind upward, and $60 \%$ of the participants chose to wind downward along the Circular line; half of the participants selected the Purple line, whereas the other half used the Blue line and continued downward before finally winding upward to the end point. In Proposal B, we found that only $10 \%$ of the participants employed the upward Circular line, and $90 \%$ of the participants selected the downward Circular line; more people opted for the Blue line. In Proposal C, $20 \%$ of the participants selected the upward Circular line, and $80 \%$ of the participants chose the downward Circular line; more people opted for the Purple line. In all the proposals, most people preferred downward routes in the hope of conforming to the direction of the start point and the end point. Moreover, because of the enhanced representation of the Circular line in Proposal A, the usage rate of the Circular line was slightly higher than that in other proposals. Different representations might affect the route choice even with the same routes (Figure 13). 


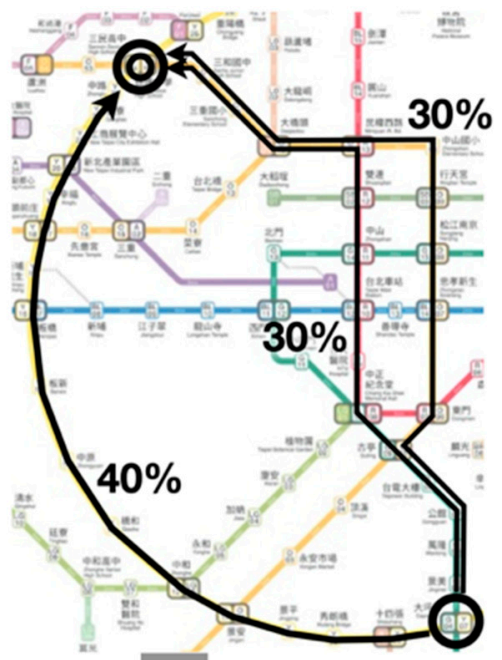

A

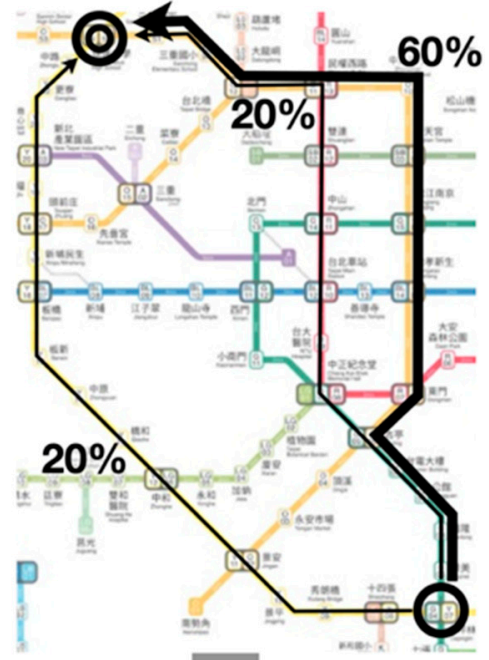

B

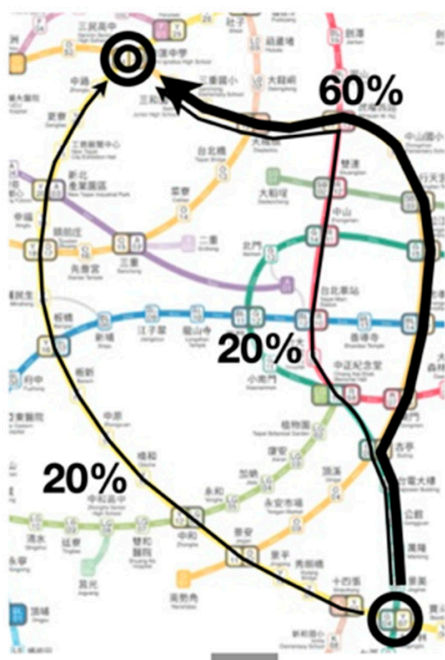

C

Figure 12. Proposal (A-C) showed avoiding a detour was regarded by most participants as more important than several transfers in shorter distance.

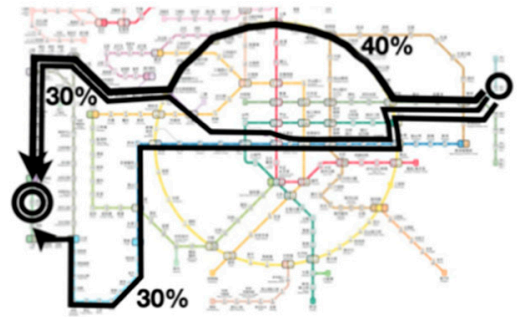

A

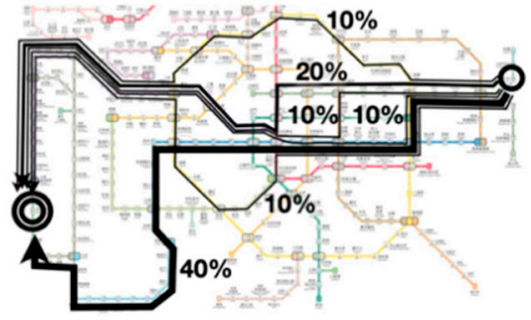

B

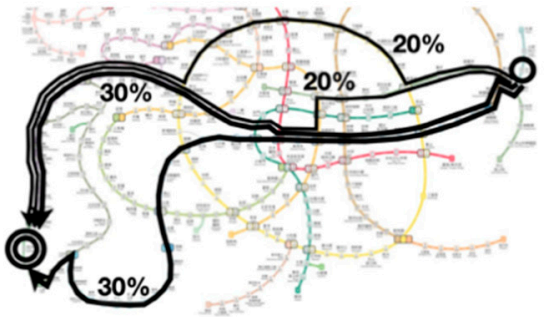

C

Figure 13. Proposal (A-C) showed different representations might affect the route choice even with the same routes.

In Task Q4, the terminal station was on the yellow Circular line, and no other route was connected to this station. In Proposal A, the Circular line was represented in a perfect circle, which differed considerably from the straight lines of other routes. Overall, $90 \%$ of the participants selected the Circular line as their main route; $60 \%$ of the participants opted for upward routes with fewer detours, whereas 30\% of the participants selected routes involving more detours but one fewer transfer. This indicated that fewer detours and transfers were both crucial appeals in route planning, and such results were also clearly demonstrated in Proposals A and Proposal C, with more people opting for upward routes (Figure 14).

Clear differences were observed among the three proposals in terms of choosing the Circular line. Because Proposal A had the most obvious circle, the Circular line in Proposal A was used more frequently in all the tasks, indicating that representations in drawings affect route planning. 


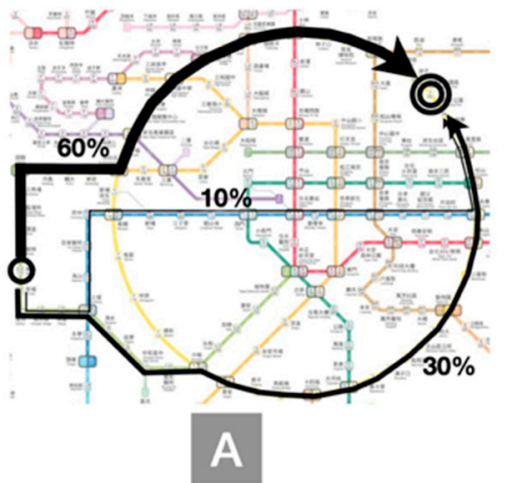

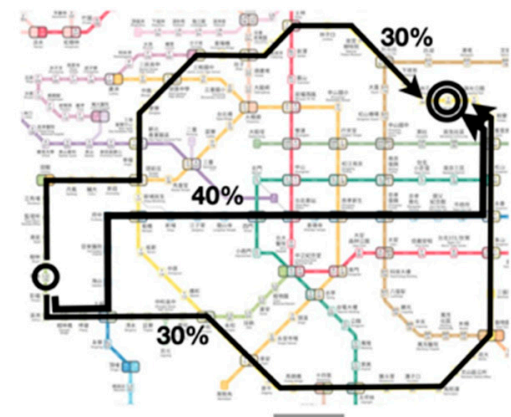

B

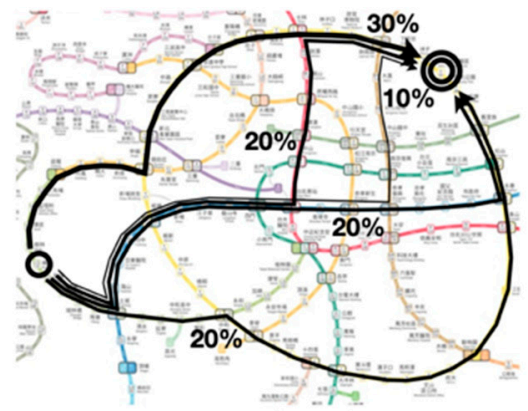

C

Figure 14. Proposal (A-C) showed fewer detours and transfers were both crucial appeals in route planning.

The route map evaluation and preference ranking conducted after the tasks were completed revealed that the participants were still more adept at using the route map with the conventional octilinear composition and were more willing to use it. By comparison, most participants held a conservative attitude regarding the use of the route composition employing the all-curve system in Proposal C. Moreover, as an explanation for their negative evaluation of the route map, they stated that it clearly did not conform to the official conventional style and seemed more suitable for special occasions. Overall, the travel time annotations added in the experiment gained positive feedback from most of the participants. Proposal B included a conventional octilinear route map with which the users were the most familiar. The route map based on the all-curve system in Proposal $C$ received an inferior evaluation by the users in terms of usability and participants' subjective preference because they were unfamiliar with it. However, these users noted that the curved composition alleviated the trouble of an excessive number of turning points along the metro lines when planning a single route and enabled them to concentrate on connections between metro lines and stations. Thus, the participants' performance in the route tasks was the highest in Proposal C among the three route maps. Furthermore, the cognitive mapping results of Proposal C suggested certain advantages; particularly, the advantage of fewer node errors was significant. Despite the absence of a significant difference between the three route maps in terms of usage performance, Proposal C (using the all-curve system-based composition) resulted in improvements in the users' cognitive memory and was equally useful for route planning as the maps using the octilinear system. Proposal A, based on the hybrid system, obtained the highest score in the participants' subjective evaluation. Because in Proposal A the Circular line was drawn with curves, the conspicuous shape helped facilitate decision-making, and the task performance was second only to that in Proposal C (Figure 15).

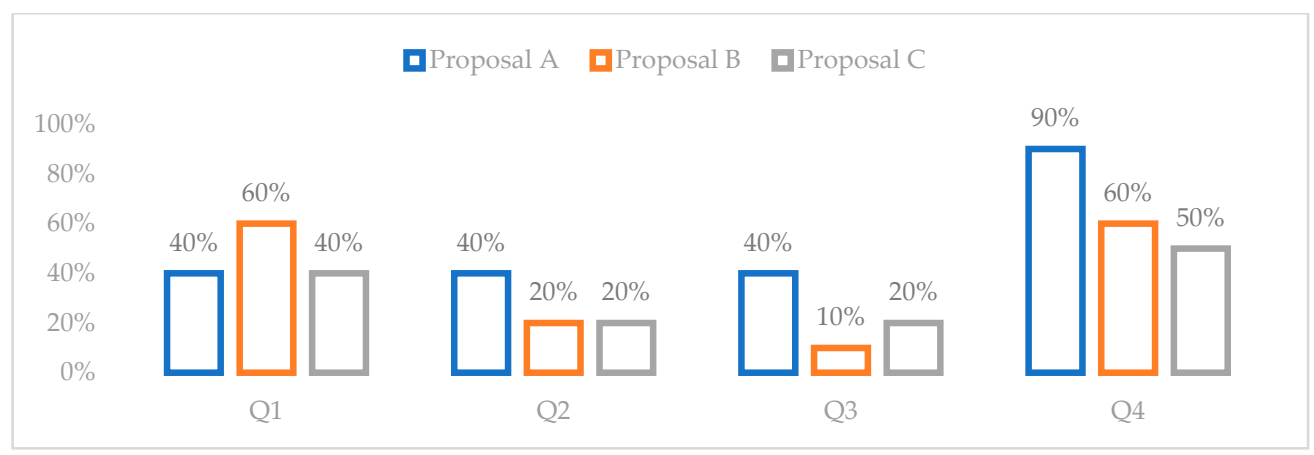

Figure 15. Differences were observed in terms of choosing the Circular line. 
Even fully schematized map representations retain topology but scale in someplace changes too much make geography becomes distorted. On the other hand, the semischematic design merges elements of the schematic map to locally simplify the representation, but retains an overall geographically correct approach. Thus, the semi-schematic design is a compromise between a fully schematic map and truly realistic geographical representation [22]. Previous studies [7,11,12] revealed that concise graphics comprising circular lines as well as vertical and horizontal key routes helped users build their spatial cognition and that route maps should be designed in accordance with local conditions.

\section{Conclusions}

The design process is viewed as a series of stages beginning with problem identification and ending with implementation. Evaluation, creativity, experimentation, and map aesthetics are part of the design activity. No one best way to a design solution can be predetermined for all maps-only principles and general approaches can guide the cartographer. The map's design elements must be arranged into a graphic composition suitable to the map's communication purpose. The elements include the map's title, scale, neat-line, symbols, and other components. Using visualization and experimentation techniques, the composition elements are arranged to satisfy the design goals [23].

The route planning tasks in Experiment 1 revealed that the users tended to favor the fewest transfers and the shortest routes. Usage experience did not result in significant differences in performance in route planning using a route map. Most errors originated in misreading transfer stations, which was associated with whether routes in a route map involved wide-angled turning points. The users tended to take Taipei Main Station as the center of the current route map, and their memory of routes progressively declined with greater distance from the main transit hub. The particular graphical representation in the current route map, such as a square-shaped route, formed "memorization graphics" in the users' cognitive memory, which facilitated identification during use. However, in drawing routes with weaker representation in cognitive memory, most participants opted to use the curved composition to represent connections between routes to grasp the relative positions among stations. Thus, in the new design proposals, in addition to addressing the problems of the current route map determined in Experiment 1, future routes and travel time information were integrated. Using three types of route designs, namely the hybrid system, the conventional octilinear design, and the all-curve system, the effects of route composition on usage behavior and cognitive memory were investigated.

Experiment 2 revealed differences in evaluation and preference regarding the three route maps; however, the difference in terms of performance in the overall route planning between the route maps was slight. The two route maps that employed the curved composition resulted in obvious advantages in route planning for specific routes. Subsequent comparison of transfer stations, nodes between routes, and angle between the start and end stations in the cognitive route map indicated that the maps using curved routes significantly enhanced cognitive memory in comparison with the conventional octilinear route map.

Users' cognitive errors could be reduced by lowering the number of nodes between routes, which was also advantageous for grasping the transfers and relative location of the route taken. As we knew, the more clearly we relate schematic maps to the critical elements of the environment represented, the more easily users can find an orientation solution [24]. Brewer [25] indicated that the internal elements of the map should maintain a linear balance. The positioning of the top of these elements should fall along a common linear position. The same can be true of elements that can align vertically. This alignment brings an orderly appearance to the map and thus produces a harmonic balance to the layout design. These alignments can be achieved in mapping software using guidelines and background grids. Compared with the current route map, an all-curve map would probably require a considerable amount of time for the public's adaptation. We recommend first converting some routes into distinct memorization graphics using the route composition 
based on the hybrid system to enhance user performance in route planning and cognitive memory. The provision of travel time information on route maps may enhance users' decision-making efficiency when using the route map. Based on the experimental results, the following suggestions regarding route map design are provided:

Avoiding excessive nodes on the routes. We found that users' cognitive load increased in the case of excessive turning points along the routes when using route maps based on the conventional octilinear system and the all-curve system, which easily caused memory errors. For large-scale routes, the turning points of the original routes may be replaced with route sections of curved composition to lower the number of nodes on the routes.

1. Avoiding unsuitable turning points on routes. This study revealed that in determining the necessity of transferring along a route, most users used route color, route turning points, and transfer station signs to confirm transfer stations along the route. Inappropriate route turning points may lead to users misreading or overlooking transfer stations. Thus, in future route map designs, route representations with sudden turning points should be avoided as much as possible.

2. Integrating clear visual centers and graphics. The experiment using the route map based on the hybrid system revealed that visual representations that include obvious central stations or conspicuously shaped routes enabled users to plan routes rapidly, assisted in their decision-making, and enhanced their memory.

3. Enlarging the areas with high transfer station density. As the size of routes grows, route map information becomes increasingly complex. This complexity may be mitigated by enlarging transfer station areas along high-volume routes and as much as possible proportional to the travel time shown, reducing information congestion and facilitating route planning.

4. Integrating travel time information. The layout of routes on a route map, which are not to scale, often results in a distorted line length ratio. Thus, misreading caused by route length may be reduced by integrating travel time annotations, thus providing users a basis for estimating travel time and increasing the efficiency of decision-making in route planning.

In this evidence-based study, we first observed the route map of Taipei's metro system and investigated proposals for new designs to identify critical factors affecting users' cognition. Then we observed users' cognitive memory and behavior regarding route maps and used diverse design approaches to examine the relationships between route map composition and cognitive mapping. Cartographic communication can only be successful if sound map design principles are fully understood and used properly [26]. A map's design should be judged only regarding the map's purpose and intended audience [27]. With limited resources, results of this study need to be repeated in the future with more participants to be verified. We expect our research findings will become effective references and suggestions for future route map design.

Author Contributions: Meng-Cong Zheng contributed to the original ideas of the paper and designed the experiments. Yao-Wei Liu performed the experiments and analyzed the experimental data un-der the supervision of Meng-Cong Zheng. Yao-Wei Liu wrote the first draft of the manuscript; Meng-Cong Zheng revised and edited it. All authors have read and agreed to the published version of the manuscript.

Funding: This research received no external funding.

Data Availability Statement: Due to confidentiality agreements, supporting data can only be made available to bona fide researchers subject to a non-disclosure agreement. Details of the data and how to request access are available from Meng-Cong Zheng (zmcdesign@gmail.com) at National Taipei University of Technology.

Acknowledgments: Special thanks for all participants and Taipei Metro who generously shared their time and experience, for the purposes of this study sections.

Conflicts of Interest: The authors declare no conflict of interest. 


\section{References}

1. Hickman, M.D.; Wilson, N.H. Passenger travel time and path choice implications of real-time transit information. Transp. Res. Part C Emerg. Technol. 1995, 3, 211-226. [CrossRef]

2. Morrison, A.J. Public transport maps in western European cities. Cartogr. J. 1996, 33, 93-110. [CrossRef]

3. Guo, Z. Mind the map! The impact of transit maps on path choice in public transit. Transp. Res. Part A Policy Pract. 2011, 45, 625-639. [CrossRef]

4. Samuels, M.; Samuels, N. Seeing with the Mind's Eye; Random House: New York, NY, USA, 1975; pp. 79-93.

5. Muehrcke, P. Maps in Modern Geography: Geographical Perspectives on the New Geography; Guelke, L., Ed.; Monograph No. 27; University of Toronto Press: Toronto, ON, Canada, 1981.

6. Power, S.; Scott, M.; Robinson, G.; Statham, I. Geological Society; Special Publications: London, UK, 1995; Volume 97, pp. 145-155.

7. Avelar, S.; Hurni, L. On the Design of Schematic Transport Maps. Cartogr. Int. J. Geogr. Inf. Geovis. 2006, 41, 217-228. [CrossRef]

8. Antes, J.; Chang, K.; Mullis, C. The Visual Effect of Map Design: An Eye-Movement Analysis. Am. Cartogr. 1985, 12, 143-155. [CrossRef]

9. Wolff, A. Drawing Subway Maps: A Survey. Informatik Forsch. Entw. 2007, 22, 23-44. [CrossRef]

10. Vertesi, J. Mind the gap: The London underground map and users' representations of urban space. Soc. Stud. Sci. 2008, 38, 7-33. [CrossRef]

11. Roberts, M.J.; Newton, E.J.; Lagattolla, F.D.; Hughes, S.; Hasler, M.C. Objective versus subjective measures of Paris Metro map usability: Investigating traditional octolinear versus all-curves schematics. Int. J. Hum.-Comput. Stud. 2013, 71, 363-386. [CrossRef]

12. Carpendale, M.S.T. A Framework for Elastic Presentation Space. Ph.D. Thesis, Simon Fraser University, Burnaby, BC, Canada, 1999.

13. Monmonier, M. How to Lie with Maps; University of Chicago Press: Chicago, IL, USA, 1996.

14. Roberts, M.J.; Gray, H.; Lesnik, J. Preference versus performance: Investigating the dissociation between objective measures and subjective ratings of usability for schematic metro maps and intuitive theories of design. Int. J. Hum.-Comput. Stud. 2017, 98, 109-128. [CrossRef]

15. Nagao, T.; Akuta, K.; Shibata, Y.; Min-Yuan, M. Constitution of Railway Map and Topological Mapping-Study of the Topological Mapping and Design Methodology of Railway Map. Bull. Jpn. Soc. Sci. Des. 2002, 48, 55-64.

16. Avelar, S. Schematic Maps on Demand: Design, Modelling and Visualization. Ph.D. Thesis, No. 14700. ETH Zurich, Zürich, Switzerland, 2002. Available online: http:/ / e-coHection.ethbib.ethz.ch (accessed on 13 June 2017).

17. Olufolajimi, O.; Siddiqui, S. Efficient automated schematic map drawing using multiobjective mixed integer programming. Comput. Oper. Res. 2015, 61, 1-17.

18. Kennedy, R.G. Problems of Cartographic Design in Geographic Information Systems for Transportation. Cartogr. Perspect. 1999, 32, 44-60. [CrossRef]

19. Zheng, M.C. Influences of different underground station map designs on map-reading and wayfinding. Geoinformatica 2020, 24, 531-555. [CrossRef]

20. Brosset, D.; Claramunt, C.; Saux, E. A Location and Action-Based Model for Route Descriptions. In GeoSpatial Semantics; Fonseca, F., Rodríguez, M.A., Levashkin, S., Eds.; Lecture Notes in Computer Science; Springer: Berlin/Heidelberg, Germany, 2007; Volume 4853, pp. 146-159.

21. Wielebski, Ł. Mapping Techniques of Spatiotemporal Relationships for a Centric Road Network Model. J. Cartogr. Geogr. Inf. 2014, 64, 269-276. [CrossRef]

22. Mohd Said, M.S.; Forrest, D. Classifying the Diversity of Bus Mapping Systems. Proc. ICA. 2018, 1, 78. [CrossRef]

23. Dent, B.D.; Torguson, J.; Hodler, T.W. Cartography: Thematic Map Design; McGraw-Hill Higher Education: New York, NY, USA, 2009.

24. Casakin, H.; Barkowsky, T.; Klippel, A.; Freksa, C. Schematic Maps as Wayfinding Aids. In Lecture Notes in Artificial IntelligenceSpatial Cognition II; Frcksa, C., Brauer, W., Habel, C., Wender, K.F., Eds.; Springer: Berlin, Germany, 2000; pp. 54-71.

25. Brewer, C. Designing Better Maps: A Guide for GIS Users; ESRI Press: Redlands, CA, USA, 2005.

26. Wood, C. The Influence of Figure and Ground on Visual Scanning Behavior in Cartographic Contexr. Ph.D. Thesis, Department of Geography, University of Wisconsin Madison, Madison, WI, USA, 1992.

27. Muehrcke, P.C. An Integrated Approach to Map Design and Production. Am. Cartogr. 1982, 9, 109-122. [CrossRef] 